\title{
DESENVOLVIMENTO DE CAPACIDADES NÃO TECNOLÓGICAS E O PAPEL DOS PROCESSOS SUBJACENTES DE APRENDIZAGEM: EXPERIÊNCIA DA PETROBRAS
}

\section{Adeslea Castro de Souza}

Mestre em Administração pela Fundação Getúlio Vargas - FGV

alcastro@petrobras.com.br (Brasil)

\section{Paulo Negueiros Figueiredo}

Doutor em Technology and Innovation Management pela Science And Technology Policy Research University Of Sussex, Inglaterra

Professor da Fundação Getúlio Vargas - FGV

pnf@fgv.br (Brasil)

\section{RESUMO}

Este artigo examina o desenvolvimento de capacidades não tecnológicas e os processos subjacentes de aprendizagem. Esse relacionamento é examinado na Petrobras (1957-2007) à base de evidências empíricas de longo prazo e de primeira mão colhidas a partir de extensivo trabalho de campo. $\mathrm{O}$ estudo revelou que a acumulação de capacidades não tecnológicas proporcionou um papel significativo na performance inovadora da empresa em estudo. Este estudo contribui, de um lado, para expandir nosso entendimento sobre a natureza das capacidades não tecnológica. De outro, o estudo chama a atenção dos gestores para a importância dessas capacidades que, embora não sejam de natureza técnica, não deveriam ser negligenciadas nos esforços gerenciais para o aprimoramento de performance inovadora em âmbito empresarial.

Palavras-chave: Capacidades não tecnológicas; Processos de aprendizagem; Performance inovadora; Petrobras. 


\section{INTRODUÇÃO}

A teoria da inovação vincula-se, enquanto legado teórico, a Schumpeter (1934/1955), mas na década de 1950, apoiadas na valiosa contribuição teórica de Penrose (1959), surgem pesquisas que avançaram ao trazer um conteúdo de questões não abordadas por Schumpeter, mais especificamente, com relação ao potencial de acumular capacidade tecnológica e organizacional, a partir da base de conhecimento como fonte de diferenças entre empresas industrializadas em termos de performance competitiva.

Na década de 1970, as mudanças significativas no desenvolvimento industrial e tecnológico nas economias em desenvolvimento chamam a atenção de Katz (1976), ao investigar, na América Latina, o desenvolvimento de capacidades tecnológicas inovadoras das empresas. Liderado por Jorge Katz, emerge um conjunto de estudos a respeito das questões relativas à natureza e direção do processo de aprendizado tecnológico, com explicação empírica e teórica dos aspectos dinâmicos da mudança técnica nos países de industrialização tardia (Dahlman \& Fonseca, 1978; Lall, 1992; Bell \& Pavitt, 1995). Essas pesquisas foram tomadas como oposição ao julgamento desfavorável da "teoria da dependência" e, por sua vez, ampliaram as fontes de ocorrência para acumulação tecnológica industrial inovadora em uma perspectiva de longo prazo (Figueiredo, 2004).

A partir do início da década de 1990, a conexão entre as duas abordagens - complexidade do processo de inovação tecnológica e dimensão dos processos subjacentes de aprendizagem nas economias em desenvolvimento - obteve vigor e relevância nas pesquisas de Hobday (1995), Kim (1998), Dutrénit (2000) e Figueiredo (2001). Esses estudos demonstraram a relação entre a dinâmica da inovação tecnológica e o crescimento produtivo com base mais empírica e comparativa entre diversas indústrias na trajetória da acumulação de capacidades tecnológicas, e atribuíram uma nova fase na literatura sobre desenvolvimento tecnológico nas empresas de países em desenvolvimento (Figueiredo, 2005).

Nesse contexto, a mudança do regime industrial no Brasil trouxe uma forte produção de estudos, por exemplo, a pesquisa de Dantas (2006) que ilustra no âmbito da abordagem da capacitação tecnológica a trajetória da acumulação de capacidades tecnológicas da indústria de petróleo estatal brasileira, ao atravessar a barreira da dependência tecnológica por assentar todo o esforço dos processos subjacentes de aprendizagem ao longo do período de 1960 a 2000.

Contudo, as análises sobre acumulação de capacidades tecnológicas identificam outros tipos de capacidade (mercadológica e administrativa) nas empresas e que, certamente, contribuem com seus processos e habilidades específicas no apoio ao complexo fluxo produtivo, mas as atenções das 
investigações estão voltadas para o desempenho produtivo. É certo que a capacidade tecnológica das empresas tem a sua importância, porém existem, no mínimo, possibilidades iguais em relação à acumulação de capacidade não tecnológica, ao envolver novos investimentos, novas formas de gestão e mudanças mercadológicas, que repercutem diretamente em seu desempenho financeiro, de modo que as empresas ocupam ao mesmo tempo um papel de liderança econômica e tecnológica.

Este artigo busca apresentar, no contexto de economia emergente, o desenvolvimento de capacidades não tecnológicas, a partir da perspectiva dos processos subjacentes de aprendizagem em gestão financeira na indústria de petróleo, Petrobras, ao longo do período de 1957-2007.

Após esta seção introdutória, a seção 1 apresenta a base analítica do artigo. A seção 2 contém uma breve revisão dos estudos existentes, posicionando o assunto deste artigo à literatura existente. A seção 3 evidencia a estrutura analítica da análise do tema proposto e o método utilizado para examinar os tipos e os níveis de capacidades não tecnológicas. A seção 4 expõe os resultados encontrados na análise do desenvolvimento de capacidades não tecnológicas, revelando os tipos e níveis identificados na análise. Na seção 5, são avaliadas as fontes para o desenvolvimento de capacidades específicas em gestão financeira. Na seção 6, por fim, apontam-se os resultados finais e as contribuições deste artigo para o desenvolvimento de capacidades não tecnológicas e as implicações dos mecanismos de aprendizagem para acumular tais capacidades específicas.

\section{BASE ANALÍTICA DO ESTUDO}

Este artigo relaciona-se com um conjunto de abordagens sobre capacidades tecnológicas em indústrias no contexto de economias em desenvolvimento e emergentes, por exemplo, Kim (1997, 1998), Tiralap (1990), Hobday (1995), Tremblay (1998), Dutrénit (2000), Ariffin (2000), Figueiredo (2001), e Tacla e Figueiredo (2003), ao reconhecer que a produção de inovação tecnológica tem natureza interativa com outras atividades, embora não tecnológicas, mas identificadas nas análises de Figueiredo (2001) e Baranãno (2003).

Não obstante, as abordagens sobre capacidades não tecnológicas em economias emergentes são quase que inexistentes, recorre-se às abordagens de países industrializados por dar ênfase às dimensões organizacionais em suas análises (Damanpour, Szabat, \& Evan, 1989; Bessant, 1991; Teece \& Pisano, 1994).

Revista de Administração e Inovação, São Paulo, v. 10, n.2, p.45-80, abr./jun. 2013. 


\subsection{Capacidade tecnológica}

Nos anos 1990, surgem as pesquisas nos países emergentes ao centrar as análises nos mecanismos de aprendizagem como fontes para acumular capacidades tecnológicas e seus efeitos na dimensão organizacional e na performance competitiva das empresas. Essas análises trouxeram bases mais amplas da trajetória de acumulação de capacidades tecnológicas nas empresas (Tiralap, 1990; Hobday, 1995; Tremblay, 1998). Os estudos de Kim (1997), Dutrénit (2000), Ariffin (2000) e Figueiredo (2001) esclarecem como os processos de aprendizagem influenciam as trajetórias de acumulação de capacidades tecnológicas no âmbito das firmas que se aproximaram da fronteira tecnológica internacional. Estudos, ainda mais recentes, avançaram ao buscar evidências da acumulação de capacidades tecnológicas das empresas que ultrapassaram a fronteira tecnológica internacional, como Dantas (2006) e Dutrénit (2007), estabelecendo um confronto com as pesquisas existentes entre os anos 1970 e 1980. Esses estudos mostraram uma perspectiva mais ampla, explorando aspectos até então inexplorados (Figueiredo, 2005).

A pesquisa de Tiralap (1990), em indústrias tailandesas, identificou que o melhor desempenho técnico e comercial tinha ligação com as mudanças tecnológicas a partir dos processos de conhecimento. Hobday (1995) examinou a trajetória de acumulação de capacidades tecnológicas das indústrias eletrônicas, no leste asiático, explorando mecanismos intraempresas e arranjos organizacionais que permitiram às empresas adquirirem conhecimentos e realizarem adaptações a partir de tecnologias externas. Esse autor preencheu uma lacuna que havia no estudo de Tiralap (1990), ao explicar as diferenças existentes entre as taxas de acumulação de competências entre empresas.

O exame de Kim (1995) atribuiu que o sucesso das empresas está agregado à existência de condições externas favoráveis para acumular competências por meio da aprendizagem tecnológica. Tremblay (1998), a partir de suas observações em alguns estudos, percebeu que não havia uma análise sistemática das influências de capacidades tecnológicas acumuladas nas dimensões organizacionais. O autor procurou superar as limitações de alguns pesquisadores e tomou como amostra as indústrias de celulose de países emergentes, ao comparar as dimensões organizacionais da capacidade tecnológica associada ao desempenho da empresa.

Dutrénit (2000) analisou, em indústria mexicana, os aspectos que restringiam a criação do conhecimento organizacional, identificando a limitação de conversão do conhecimento individual em organizacional nos diferentes departamentos e unidades industriais, indicando que a trajetória de 
acumulação de competências tecnológicas é fortemente influenciada pelo processo de aprendizagem interno à empresa.

A pesquisa de Figueiredo (2001) buscou a relação entre as trajetórias de acumulação de competências tecnológicas, os processos de aprendizagem e a melhoria de performance operacional de duas grandes usinas siderúrgicas brasileiras, apontando as diferenças observadas na intensidade, o esforço para adquirir conhecimentos de fontes internas e externas e a conversão dos processos de aprendizagem individual em organizacional, que influenciam as trajetórias tecnológicas das empresas, a expansão dos resultados operacionais e a valorização financeira no mercado acionário das empresas. Figueiredo (2001) identificou outras capacidades, embora não tecnológicas na dimensão organizacional, que contribuíram para a vantagem competitiva das indústrias siderúrgicas.

Dantas (2006) examinou a trajetória da acumulação de capacidades tecnológicas da indústria de petróleo brasileira (Petrobras), buscando a relação entre as várias capacidades técnicas da empresa e as características da rede de conhecimento desenvolvida a partir das competências adquiridas pela assimilação de tecnologia dos países industrializados. A indústria petrolífera passou a produzir tecnologia adaptada às suas necessidades e, logo, impulsionou a criação de tecnologia própria. A partir de 2000, a Petrobras passou a ser referência tecnológica internacional na exploração de petróleo em águas profundas, por desenvolver tecnologia pioneira no mundo.

Alguns estudos revelam a ligação das capacidades complementares (administrativas) com o complexo fluxo de produção tecnológica, contudo não são exploradas as suas contribuições, inclusive as abordagens e os debates acadêmicos estão voltados para a competência das áreas vitais (capacidades técnicas) das indústrias. Na visão de Teece e Pisano (1994), as organizações de sucesso são aquelas que têm desenvolvidas suas capacidades dinâmicas à medida que os processos organizacionais se relacionam com as estratégias e rotinas organizacionais.

\subsection{Capacidade não tecnológica}

No contexto em que os países medem o impacto da mudança, particularmente a tecnológica, é necessário ser reconhecida a importância da inovação não tecnológica (organizacional, marketing, finanças, logística, entre outras) para o desempenho econômico das empresas; ou seja, estimular as mudanças organizacionais provocadas pelas mudanças no processo tecnológico, as quais geram efeitos mensuráveis nos resultados das empresas.

A partir da revisão de 2005, o Manual de Oslo incluiu a inovação não tecnológica ao coligir experiências de pesquisas anteriores para modelar a estrutura de mensuração da inovação não 
tecnológica, passando a incluir as inovações organizacionais (finanças, logísticas, vendas) e de marketing, também fez considerações acerca das pesquisas de inovação conduzidas nos países industrializados e, sobretudo, nos países em desenvolvimento.

O Relatório Analítico da Organisation de Coopération et de Développment Économiques (OCDE) sobre Technology: Productivity and Job Creation (1997) discutiu um conjunto de pesquisas que indica que as mudanças tecnológicas e organizacionais estão altamente interligadas, por exemplo, a pesquisa realizada pelo Australian Bureau of Statistics (ABS), referente ao período 1993-1994, mediu a extensão da ocorrência de inovações não tecnológicas em indústria australiana. Como não havia normas internacionais desenhadas, a análise teve tratamento experimental, por isso não verificou o impacto dessas inovações sobre as inovações tecnológicas no desempenho das empresas. No entanto, foi possível identificar que $15 \%$ das empresas australianas produziram inovações organizacionais, em comparação com 13\% para inovações tecnológicas.

Com o objetivo de identificar e avaliar os fatores organizacionais e de gestão que contribuem para o sucesso dos processos de inovação tecnológica, Barañano (2005) contribuiu ao pesquisar as capacidades complementares de empresas portuguesas. A autora expõe que a falta de capacidade complementar afeta as áreas de capacidades essenciais da organização. A inovação não tecnológica é uma condição necessária à empresa para explorar qualquer inovação tecnológica, normalmente acontece em organização que tem um ambiente administrativo que influencia também o seu desempenho (Baranãno, 2003).

Teece (1980) enfatiza que o desempenho do modelo que sugere os insights adicionais a partir do estudo da inovação tecnológica pode ser aplicado ao estudo da inovação não tecnológica (administrativa). O autor analisa o controle do capital intelectual monitorando a gestão do conhecimento sobre a eficácia da capacidade da organização, identificando que a geração de novos produtos ou processos de inovação tem um impacto significativo sobre a inovação e eficácia organizacional.

As abordagens de Ettlie (1988), Bessant (1991), Teece e Pisano (1994) e Figueiredo (2001) defendem a integração funcional das práticas dos serviços organizacionais básicos com o setor produtivo. A integração multifuncional serve, também, como um dos pilares da eficiência do desenvolvimento de processos, igualmente associada à vantagem competitiva global da empresa (Pisano, 1997; Tsekouras, 1998). Entretanto, esses vínculos de cooperação com o setor produtivo exigem dos serviços básicos capacidades específicas para auxiliar as necessidades dos processos tecnológicos, principalmente em se tratando de recursos econômico-financeiros (Figueiredo, 2001).

Revista de Administração e Inovação, São Paulo, v. 10, n.2, p.45-80, abr./jun. 2013. 
Este artigo dispõe-se da moldura analítica apresentada na Figura 1. A estrutura superior está relacionada às evidências trazidas por Dantas (2006), que ilustra a trajetória da acumulação de capacidades tecnológicas da Petrobras entre o período de 1960 a 2002. A estrutura inferior dessa figura é atribuída ao exame empírico do tema deste artigo, a disposição organizacional da gestão financeira da Petrobras, que apoia e auxilia o complexo fluxo do processo tecnológico. Portanto, o presente artigo examina o desenvolvimento de capacidades não tecnológicas e o papel dos processos subjacentes de aprendizagem, para evidenciar as competências específicas em finanças, que auxiliaram a trajetória tecnológica da indústria ao longo do período de 1957 a 2007.

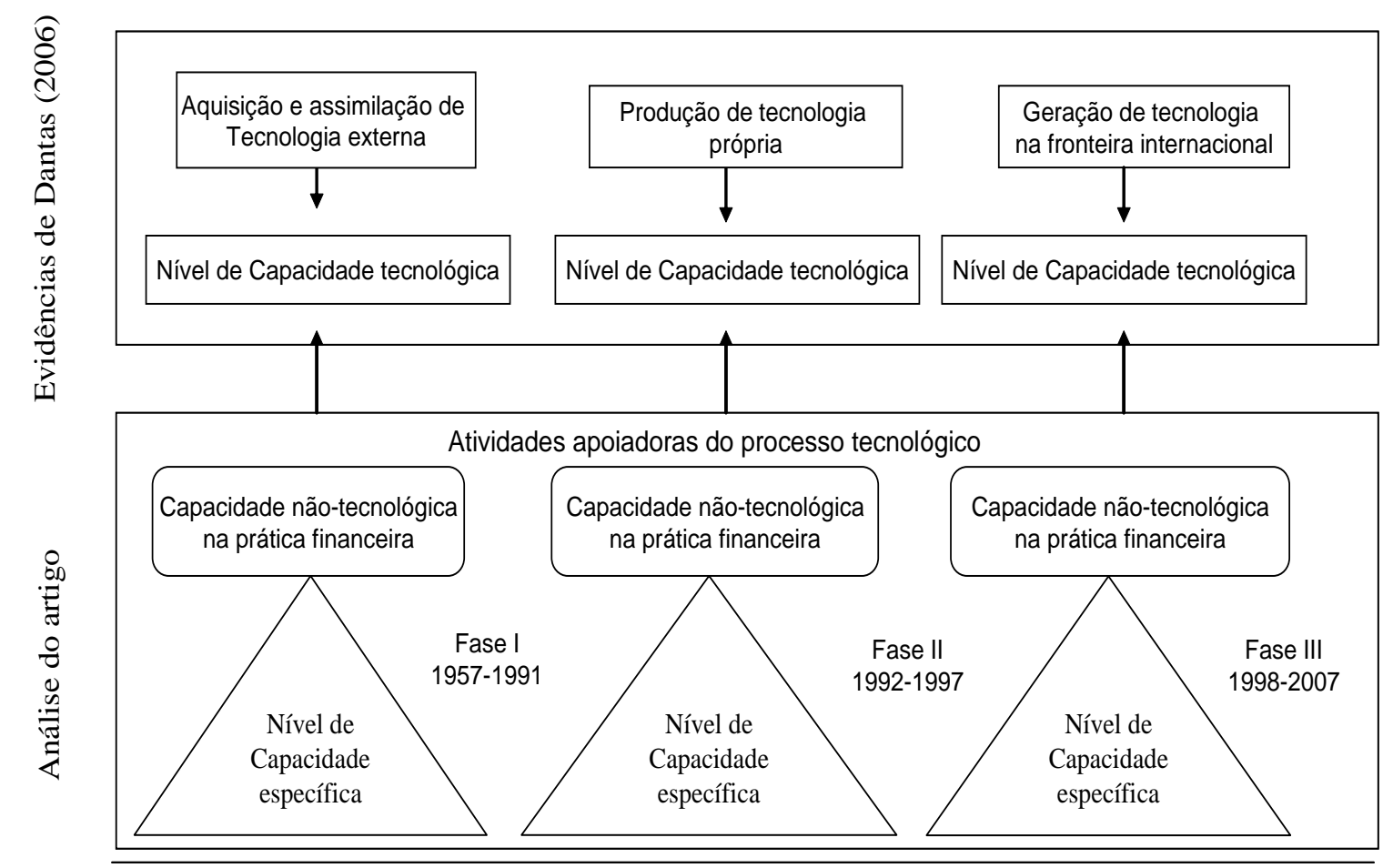

Figura I: Moldura analítica do estudo

Fonte: Derivada do trabalho de campo

Damanpour, Szabat e Evan (1989) destacam que as inovações podem ser vistas sob dois aspectos: de natureza técnica ou de natureza administrativa. As inovações técnicas são, segundo os autores, aquelas que ocorrem no componente operacional e afetam o sistema técnico de uma organização, sendo que esse sistema consiste dos equipamentos e métodos de operação utilizados para transformar matéria-prima ou informações em produtos ou serviços. Já as inovações administrativas, de acordo com os autores, são aquelas que ocorrem no componente administrativo (serviços básicos 
organizacionais) e afetam o sistema social de uma organização, consistindo na introdução de um novo sistema gerencial.

A compreensão dessas inovações, aqui denominadas inovações não tecnológicas, torna-se relevante diante do ambiente extremamente competitivo das organizações e estão intimamente ligadas não só aos princípios convencionais de qualidade e produtividade, mas, também, a um novo princípio de qualidade que aborda o crescimento integrado da dimensão organizacional das empresas, que se traduz em capacidades dinâmicas.

À luz da literatura das capacidades dinâmicas, a trajetória histórica de desenvolvimento percorrida por uma empresa resulta identificar diferentes recursos e capacidades nas estruturas organizacionais, a consequência é ter meios de explicar como a empresa consegue desenvolver certas estratégicas. Portanto, as capacidades organizacionais, alicerce das competências, precisam ser dinâmicas para a adaptação exigida pelo contexto competitivo (Teece, Pisano, \& Shuen, 1997).

Nesse contexto, insere-se o conceito de capacidades dinâmicas, como a capacidade de renovação das competências organizacionais ao longo do tempo, objetivando-se a criação e a manutenção das vantagens competitivas. Ao abordar as capacidades dinâmicas, Penrose (1959) afirma que elas provêm de um modelo coerente e inovador de como as firmas desenvolvem vantagens competitivas. Por fim, sintetiza o conceito em um modelo aprendido, estável, de atividade coletiva, por meio do qual a organização sistematicamente gera e modifica suas rotinas organizacionais (Winter, 2006).

A propósito, as pesquisas sobre capacidades não tecnológicas, mais especificamente aquelas relacionadas às finanças, pouco têm merecido a atenção dos pesquisadores. Por um lado, o desenvolvimento tecnológico implica a criação de estratégias financeiras, logo, constitui-se um dos núcleos de geração de capacidades dinâmicas.

No ambiente de economia emergente, este artigo tem o propósito de impulsionar e somar aos poucos estudos sobre capacidade não tecnológica, por trazer um tema pouco explorado e com pouca profundidade na literatura, e por analisar a participação e o posicionamento dos serviços organizacionais básicos no sistema organizacional da empresa com a prática de atividades apoiadoras essenciais à trajetória da acumulação de capacidades tecnológicas das empresas. 


\section{BASE CONCEITUAL}

Nesta seção, apresentam-se os conceitos básicos e os modelos analíticos à luz das análises sobre acumulação de capacidades tecnológicas, no contexto de economias emergentes, que foram adaptados e utilizados para o exame da acumulação de capacidades não tecnológicas nas atividades dos serviços básicos organizacionais, em especial gestão financeira, da empresa analisada.

\subsection{Capacidade como fonte de vantagem competitiva}

Esta abordagem considera a capacidade como a base de conhecimento produtivo e organizacional e, por sua vez, a fonte mais importante de vantagem competitiva (distintiva), de heterogeneidade e de rendimento ou retorno diferencial das firmas, em longo prazo. Analisando de modo geral, os fenômenos dentro da firma (condições pelas quais os recursos empregados por ela geram retornos) ocorridos nos processos organizacionais e produtivos explicam o seu desempenho (eficiência e eficácia dos recursos organizacionais e capacidades) em um ambiente competitivo e dinâmico.

Penrose (1959) amplia a formação do termo 'capacidade', dentro da teoria de recursos nas organizações como um grupo de recursos, e a capacidade organizacional possibilitando a mobilização de ativos de naturezas diversas, mas direcionada ao processo de inovação. No caso da abordagem das capacidades dinâmicas mais importantes do que o estoque atual de recursos, é a capacidade de acumular e combinar novos recursos em novas configurações que gerem fontes adicionais de recursos. O desenvolvimento de capacidades combinado com as habilidades organizacionais e as inovações são identificados como capacidades dinâmicas específicas à firma para conduzir as mudanças no ambiente (Teece, Pisano, \& Shuen, 1997).

Com a finalidade de ampliar a dinâmica de capacidade baseada em recursos, Teece e Pisano (1994) propuseram a abordagem de estratégia baseada em capacidades dinâmicas. Segundo os autores, o termo 'capacidade' tem a finalidade de enfatizar o papel-chave do gerenciamento estratégico na função de adaptar, integrar e requerer novas configurações nas especialidades da empresa. Já a palavra 'dinâmica' tem o sentido de que as capacidades devem acompanhar e predizer as mudanças em seu ambiente, observando a velocidade das inovações e capacitando as empresas a responderem rapidamente às demandas perceptíveis e veladas desse ambiente, inclusive a criação de novas capacidades (Teece \& Pisano, 1994).

Revista de Administração e Inovação, São Paulo, v. 10, n.2, p.45-80, abr./jun. 2013. 
Tidd, Bessant e Pavitt (1997) salientam que há um reconhecimento cada vez maior do mercado em prol daquelas organizações que podem mobilizar seus recursos organizacionais (conhecimento, experiência e capacidade) para criar e programar novos produtos, processos e serviços, para isso a acumulação, a manutenção e a geração de novas capacidades estão condicionadas ao processo cumulativo de aprendizagem nas organizações (Kim, 1998; Figueiredo, 2003). Um dos méritos que se pode destacar na abordagem das capacidades dinâmicas é a valorização promovida pelo aprendizado, visto como fundamental no processo de criação, desenvolvimento e acumulação de capacidades.

Além disso, a abordagem de capacidades dinâmicas consegue explicar como empresas que operam em um mesmo ambiente podem apresentar resultados completamente distintos entre elas, construindo trajetórias de sucesso, e outras de insucesso.

\subsection{Acumulação de capacidade tecnológica no contexto de países em emergentes}

Uma das características tecnológicas-chave das empresas que operam no contexto de economias emergentes - ou de industrialização recente - é que normalmente iniciam o seu negócio a partir da tecnologia que adquiriram de empresas industrializadas. Ao iniciar as suas atividades, não dispõem sequer das capacidades tecnológicas básicas. Para tornarem-se competitivas e aproximaremse de empresas da "fronteira tecnológica internacional", elas têm que se engajar em um processo de aprendizagem para construir e acumular sua capacidade tecnológica (Figueiredo, 2004).

Numa perspectiva mais ampla, a discussão sobre a capacidade tecnológica está, portanto, relacionada ao debate sobre como alguns países emergentes conseguiram internalizar o processo de mudança tecnológica, reduzindo o hiato em relação aos países avançados. As capacidades tecnológicas das empresas se desenvolveram por meio de processos de aprendizado adaptativo e incremental, realizando esforços tecnológicos para adquirir conhecimentos, aptidões e experiências, os quais formaram a acumulação de capacidades tecnológicas, e suas intenções tinham como estratégica principal focar no catch-up, ou seja, alcançar as empresas localizadas na fronteira tecnológica internacional. Para isso, os esforços tecnológicos foram conduzidos por meio de diferentes mecanismos de aprendizado, que podem possuir um caráter explícito e deliberado em maior ou menor extensão.

Para Figueiredo (2004), as empresas em economias emergentes, geralmente, iniciam em condição de não competitividade no mercado mundial ("infância industrial”). O problema básico da maturidade industrial é acumular capacidade tecnológica para tornar-se e manter-se competitiva nesse

Revista de Administração e Inovação, São Paulo, v. 10, n.2, p.45-80, abr./jun. 2013. 
mercado (Bell, 1984). Tal acumulação envolve uma sequência evolutiva e cumulativa de estágios mais simples a complexos (Katz, 1987; Lall, 1992; Bell \& Pavitt, 1993).

Portanto, as empresas que operam em economias emergentes parecem percorrer uma trajetória diferente das tecnologicamente inovadoras que produzem em economias industrializadas: a acumulação de capacidade tecnológica nesse ambiente costuma seguir uma rota diferenciada, pois tende a inverter a sequência "inovação-investimento-produção", característica típica de economias industrializadas. Nesse caso, as empresas industrializadas apresentam a trajetória do tipo "produçãoinvestimento-inovação" (Dahlman, Ross-Larsen, \& Westphal, 1987).

Essa perspectiva alinha-se ao modelo desenvolvido em Kim (1997), que ilustra como esse tipo de empresa segue uma trajetória baseada num modelo de três estágios: (i) aquisição; (ii) assimilação; e (iii) aprimoramento. Durante seu estágio inicial, a ênfase técnica recai sobre a engenharia e, em menor parte, sobre o desenvolvimento e pesquisa. A assimilação bem-sucedida de tecnologia de produção e a ênfase crescente em promoção de exportação, juntamente à crescente capacidade científica e tecnológica local, conduzem ao gradual aprimoramento da tecnologia.

Ao proceder, ao longo dessa trajetória de aquisição, assimilação e aprimoramento, as empresas em economias emergentes invertem a sequência dos países tecnologicamente avançados, a partir desse ponto, entram no estágio de geração de inovação própria (Lall, 1992). De acordo com Figueiredo (2004), as empresas de países em economias emergentes se desenvolvem gradualmente, seguindo uma trajetória inversa daquela dos países industrializados, ou seja, sua trajetória é formada pela sequência: produção, investimento, inovação.

As abordagens citadas por Figueiredo (2004) demonstram o dinamismo tecnológico de empresas e países. Por exemplo, em um passado distante, a China exportava tecnologia para a Europa. No século passado, países, antes considerados tecnologicamente atrasados, tornaram-se líderes tecnológicos mundiais, tais como Alemanha, Estados Unidos, Japão, Coreia do Sul e Finlândia, em indústrias como a de semicondutores, química, farmacêutica, eletrônica de consumo, biológica, automobilística, aço, tecnologia de informação e telefonia móvel.

Segundo Figueiredo (2004), é possível começar com o mais baixo nível de capacidade tecnológica e evoluir para níveis muito avançados. Mas isso exige esforços em aprendizagem tecnológica para acelerar a acumulação de capacidades inovadoras. Seguindo esse exemplo, países, como Alemanha, Estados Unidos e Noruega, considerados líderes em tecnologia, na década de 1960, exportaram tecnologias para atender ao dinamismo da indústria de petróleo no Brasil. Por circunstância oportuna, a indústria de petróleo nacional desenvolveu suas capacidades tecnológicas a partir da aquisição de tecnologia de países industrializados.

Revista de Administração e Inovação, São Paulo, v. 10, n.2, p.45-80, abr./jun. 2013. 
Nesse sentido, Dantas (2006) faz referência à indústria de petróleo nacional, que atingiu catchup da fronteira tecnológica internacional, em 2000, aprofundando as suas capacidades tecnológicas e, atualmente, a Petrobras mantém-se com outras indústrias brasileiras no mercado competitivo internacional. Logo, as empresas de países no contexto de economias emergentes têm se localizado em todos os pontos das capacidades tecnológicas e se preocupam com a construção de capacidades estratégicas e inovativas mais avançadas, como a Petrobras e outras que operam e contribuem para empurrar e deslocar a fronteira tecnológica internacional. (Figueiredo, 2008).

Desse modo, é possível começar com o mais baixo nível de capacidade tecnológica e evoluir para níveis muito avançados. Contudo, para Figueiredo (2004), isso exige esforços em aprendizagem tecnológica para acelerar a acumulação de capacidades inovadoras em tecnologia e em âmbito organizacional.

\subsection{Desenvolvimento de capacidade não tecnológica}

O desenvolvimento de capacidade não tecnológica está baseada na geração de estratégias nos serviços disponibilizados a clientes internos e externos, como também pode ser o processo pelo qual uma empresa diferencia-se das outras ao criar inovação não tecnológica, sob a forma de novos serviços ou práticas de gestão administrativa corporativa como fontes potenciais de diferenciação, quando a capacidade da empresa para inovar continuamente lhe confere uma vantagem dinâmica (Teece, Pisano, \& Shuen, 1997).

Chandler (1962) fornece evidências para apoiar o argumento de que uma das principais inovações na gestão organizacional da empresa pode levar à melhoria de longo prazo para o desempenho inovador na organização. De acordo com Dosi (1997), Lundvall (1992) e OECD (2005), a inovação não tecnológica diz respeito ao modo da organização, ao mercado ou a outros elementos ou aspectos inovadores na atividade econômica.

Segundo a definição da OECD (2005), as inovações organizacionais ou administrativas adotam técnicas avançadas de gestão (por exemplo, gestão de qualidade total, gestão financeira, just in time na produção, entre outras); novas formas de organização do trabalho; a modificação das estruturas organizacionais (como, por exemplo, a passagem de estruturas funcionais para estruturas em rede); e a adoção de orientações estratégicas inteiramente novas ou sensivelmente modificadas. Essas inovações são requisitos para as inovações tecnológicas e para que outras formas de inovação tenham sucesso.

Revista de Administração e Inovação, São Paulo, v. 10, n.2, p.45-80, abr./jun. 2013. 
Alguns estudos têm colaborado para identificar e definir os fatores de inovação não tecnológica para o sucesso ou insucesso de inovações tecnológicas. Baranãno (2005) destaca que para a dimensão da inovação organizacional é bastante difícil de propor uma medição dos méritos organizacionais e é provável que isso seja a razão do pequeno esforço feito em definir um vigamento teórico e medidas precisas para o desenvolvimento de inovação não tecnológica. A autora relaciona, ainda, o desenvolvimento de inovação não tecnológica a três fatores: (i) sucesso de inovação tecnológica; (ii) características da organização inovadora; e (iii) inovação organizacional e não organizacional.

Para a OCDE (2005), as inovações não tecnológicas desempenham um papel central na organização por envolver o desenvolvimento e a adoção de mudanças de um novo método organizacional nas práticas de negócio da empresa, no local de trabalho e nas relações externas.

Por fim, este artigo reconhece a importância da inovação não tecnológica (inovação organizacional e gerencial) para o desempenho econômico das empresas no sucesso de inovações tecnológicas.

\subsection{Mensuração dos níveis e tipos de capacidade não tecnológica}

A abordagem de Bell (1984) observa que a empresa em industrialização começa a operar na circunstância de não ser competitiva no mercado mundial (a chamada "infância industrial"). A acumulação de competências tecnológicas é questão básica para alcançar a "maturidade industrial" e, assim, tornar-se e permanecer competitiva no mercado mundial. Segundo Lall (1992), a empresa, antes de alcançar a maturidade, o nível de competência ou de capacitação tecnológica nas várias funções tecnológicas, pode variar em diferentes níveis de capacidades tecnológicas. Por sua vez, as citações dos autores podem ser extensivas à formação de capacidades não tecnológicas produzidas pelos setores não produtivos da empresa, que, por meio de suas atividades organizacionais básicas, apoiam o fluxo produtivo da empresa.

Portanto, a moldura de análise de capacidades tecnológicas foi adaptada de Figueiredo (2001) para descrever o desenvolvimento de capacidades não tecnológicas de empresas no contexto de economias emergentes. A estrutura permite diferenciar os níveis de capacidades não tecnológicas para diversas funções não tecnológicas que executam atividades básicas. A Tabela 1 proporciona uma base para a descrição do desenvolvimento das atividades financeiras apoiadoras do processo tecnológico da empresa, desde o nível básico, onde estão presentes apenas as capacidades elementares para executar as atividades de rotinas básicas e com melhorias organizacionais, até os níveis de capacidades para

Revista de Administração e Inovação, São Paulo, v. 10, n.2, p.45-80, abr./jun. 2013. 
desenvolver atividades financeiras inovadoras com diferentes graus de complexidade e escopo para as várias funções não produtivas. O modelo de análise distingue três diferentes tipos de função não tecnológica determinantes nas atividades financeiras da Petrobras, e demonstra com precisão os avanços sucessivos de níveis básicos para os níveis subsequentes até atingir o nível absoluto do modelo, por executar atividades financeiras com a implantação de novos arranjos econômicofinanceiros de grande complexidade.

Para analisar e identificar o desenvolvimento de capacidades não tecnológicas com detalhes, alinham-se às práticas financeiras requeridas pelo intenso fluxo produtivo da empresa as rotinas organizacionais, que são dispostas em colunas, e os seis níveis de complexidade, que são designados por: 1) básico; 2) básico renovado; 3) intermediário superior; 4) superior; 5) avançado; e 6) fronteira internacional. 
Tabela 1: Modelo de descrição de capacidades não tecnológicas da gestão financeira

\begin{tabular}{|c|c|c|c|}
\hline $\begin{array}{c}\text { Níveis de } \\
\text { Capacidade }\end{array}$ & $\begin{array}{c}\text { Gestão de Operações } \\
\text { Financeiras } \\
\end{array}$ & $\begin{array}{c}\text { Gestão de Captações de } \\
\text { Financiamento } \\
\end{array}$ & Gestão do Caixa \\
\hline \multicolumn{4}{|c|}{ CAPACIDADES INOVADORAS } \\
\hline $\begin{array}{l}\text { Nível (6) } \\
\text { Fronteira } \\
\text { Internacional }\end{array}$ & $\begin{array}{l}\text { Realizar a gestão de } \\
\text { bonds; operações de } \\
\text { troca de títulos; } \\
\text { operações de hedge; } \\
\text { operações de derivativos; } \\
\text { e operações de captação } \\
\text { de recursos financeiros } \\
\text { no mercado financeiro } \\
\text { nacional e internacional } \\
\text { de curto e longo prazo; e } \\
\text { executar as mesmas } \\
\text { operações para todas as } \\
\text { empresas do grupo } \\
\text { empresarial. }\end{array}$ & $\begin{array}{l}\text { Refinamento na contratação de } \\
\text { Project Finance e Paper } \\
\text { Company; captação de recursos } \\
\text { no exterior e no mercado } \\
\text { interno; modelagens de } \\
\text { operações financeiras com } \\
\text { parceiros internacionais, } \\
\text { organizando projetos de } \\
\text { afretamentos e novas } \\
\text { tecnologias; planejamento } \\
\text { financeiro e fiscal para redução } \\
\text { de custos operacionais; e manter } \\
\text { o relacionando dos novos } \\
\text { projetos financeiros com os } \\
\text { parceiros de acordos } \\
\text { empresariais. }\end{array}$ & $\begin{array}{l}\text { Criação do Centro de } \\
\text { Operações Financeiras para } \\
\text { concentrar as atividades de } \\
\text { movimentação financeira } \\
\text { (processos de pagamentos e } \\
\text { recebimentos) de todas as } \\
\text { empresas do grupo empresarial } \\
\text { num único local, inclusive as } \\
\text { empresas internacionais. }\end{array}$ \\
\hline $\begin{array}{l}\text { Nível (5) } \\
\text { Avançado }\end{array}$ & $\begin{array}{l}\text { Gestão de suporte nas } \\
\text { operações de emissão de } \\
\text { ADR no exterior; manter } \\
\text { alinhados os fluxos } \\
\text { financeiros das } \\
\text { operações de aplicação x } \\
\text { captação, e operações de } \\
\text { troca de papéis com } \\
\text { prazos favoráveis ao } \\
\text { fluxo operacional; e } \\
\text { efetuar operações de } \\
\text { hedging para proteção } \\
\text { dos recursos em moeda } \\
\text { estrangeira. }\end{array}$ & $\begin{array}{l}\text { Operações estruturais; avaliação } \\
\text { dos resultados e inovação nos } \\
\text { processos de gestão de projetos; } \\
\text { estruturação de operação de } \\
\text { emissão de ADR na Bolsa de } \\
\text { Valores norte-americana; e } \\
\text { gestão de operações } \\
\text { diferenciadas de Project } \\
\text { Finance. }\end{array}$ & $\begin{array}{l}\text { Criação do limite de } \\
\text { competência por meio } \\
\text { eletrônico; executar liquidação } \\
\text { financeira por meio de sistema } \\
\text { informatizado sem tramitação } \\
\text { de documento; implementar } \\
\text { índice de desempenho das } \\
\text { rotinas executadas; elaborar o } \\
\text { fluxo de caixa de longo prazo; } \\
\text { codificação dos procedimentos } \\
\text { e normas internas } \\
\text { organizacionais das atividades } \\
\text { da Gestão do Caixa; e rever } \\
\text { Manual Financeiro, } \\
\text { disponibilizando em sistema de } \\
\text { rede. }\end{array}$ \\
\hline $\begin{array}{l}\text { Nível (4) } \\
\text { Superior }\end{array}$ & $\begin{array}{l}\text { Praticar renovação de } \\
\text { empréstimos com taxa } \\
\text { mais atraente no } \\
\text { mercado internacional; } \\
\text { manter os prazos dos } \\
\text { fluxos financeiros e } \\
\text { operacionais; e } \\
\text { minimizar a necessidade } \\
\text { de captação financeira. }\end{array}$ & $\begin{array}{l}\text { Elaboração de análise } \\
\text { econômico-financeira de } \\
\text { projetos de parcerias; análise de } \\
\text { viabilidade e riscos junto às } \\
\text { unidades operacionais de novos } \\
\text { projetos; intensificar a } \\
\text { elaboração de vários projetos de } \\
\text { parcerias, diversificando a } \\
\text { metodologia de estudos } \\
\text { conforme parceiros; e criação e } \\
\text { montagem de projetos } \\
\text { estruturados (Project Finance) } \\
\text { com empresas do sistema para } \\
\text { buscar financiamentos no } \\
\text { exterior e agência de fomento. }\end{array}$ & $\begin{array}{l}\text { Implantação de padronização } \\
\text { das atividades e rotinas das } \\
\text { unidades de pagamento } \\
\text { descentralizadas; criar } \\
\text { atividade de conformidade e } \\
\text { inconformidade dos processos } \\
\text { financeiros; controlar os } \\
\text { processos devolvidos; criar } \\
\text { fluxo de caixa de curto prazo; } \\
\text { analisar os processos } \\
\text { financeiros; e implementar } \\
\text { execução financeira das } \\
\text { obrigações e direitos das } \\
\text { parceiras. }\end{array}$ \\
\hline
\end{tabular}

Revista de Administração e Inovação, São Paulo, v. 10, n.2, p.45-80, abr./jun. 2013. 


\begin{tabular}{|c|c|c|c|}
\hline $\begin{array}{c}\text { Níveis de } \\
\text { Capacidade }\end{array}$ & $\begin{array}{l}\text { Gestão de Operações } \\
\text { Financeiras }\end{array}$ & $\begin{array}{c}\text { Gestão de Captações de } \\
\text { Financiamento }\end{array}$ & Gestão do Caixa \\
\hline \multicolumn{4}{|c|}{ CAPACIDADES ROTINEIRAS } \\
\hline $\begin{array}{l}\text { Nível (3) } \\
\text { Intermediário } \\
\text { Superior }\end{array}$ & $\begin{array}{l}\text { Implementação de } \\
\text { controles das operações } \\
\text { pela criação de } \\
\text { ferramenta de } \\
\text { informática. }\end{array}$ & $\begin{array}{l}\text { Adaptação das práticas de } \\
\text { gestão de projetos; } \\
\text { identificação de riscos; } \\
\text { gerenciar recursos de terceiros } \\
\text { (parceiros); e melhor } \\
\text { utilização das ferramentas de } \\
\text { gestão. }\end{array}$ & $\begin{array}{l}\text { Aperfeiçoar sistema de gestão } \\
\text { de execução financeira em } \\
\text { moeda nacional; criar } \\
\text { controles da execução } \\
\text { financeira; implementar a } \\
\text { cobrança e controles em } \\
\text { moeda estrangeira; gerenciar } \\
\text { saldos de contas bancárias; e } \\
\text { criar controle de cobranças. }\end{array}$ \\
\hline $\begin{array}{l}\text { Nível (2) } \\
\text { Básico Renovado }\end{array}$ & $\begin{array}{l}\text { Melhor gestão das } \\
\text { disponibilidades do } \\
\text { caixa; criar a mesa de } \\
\text { operações financeiras na } \\
\text { busca das melhores } \\
\text { taxas no mercado } \\
\text { financeiro interno e } \\
\text { externo; e contato mais } \\
\text { ativo com as instituições } \\
\text { financeiras. }\end{array}$ & $\begin{array}{l}\text { Gestão dos financiamentos } \\
\text { aprovados; elaboração de } \\
\text { novos projetos, identificando } \\
\text { novas formas de } \\
\text { financiamento; e utilização de } \\
\text { sistema de gestão para } \\
\text { acompanhamento dos } \\
\text { financiamentos de forma } \\
\text { básica. }\end{array}$ & $\begin{array}{l}\text { Conferir processos } \\
\text { financeiros; verificar limites } \\
\text { de competência; confrontar } \\
\text { documento fiscal com } \\
\text { autorização de compra; fazer } \\
\text { uma análise tributária do } \\
\text { documento fiscal; e levantar } \\
\text { dados de subsídio para } \\
\text { elaboração do fluxo de caixa. }\end{array}$ \\
\hline $\begin{array}{l}\text { Nível (1) } \\
\text { Básico }\end{array}$ & $\begin{array}{l}\text { Aplicação financeira e } \\
\text { resgate da } \\
\text { disponibilidade de caixa; } \\
\text { operação de contratação } \\
\text { de câmbio; liquidação } \\
\text { financeira das } \\
\text { obrigações em moeda } \\
\text { estrangeira; e cobertura } \\
\text { de eventuais déficits do } \\
\text { caixa em moeda } \\
\text { nacional e estrangeira. }\end{array}$ & $\begin{array}{l}\text { Elaboração de estudos de } \\
\text { viabilidade de captação de } \\
\text { financiamentos para: } \\
\text { aquisição de tecnologia de } \\
\text { países industrializados e } \\
\text { construção de plantas } \\
\text { industriais; e analisar as } \\
\text { melhores alternativas de } \\
\text { financiamento no mercado } \\
\text { financeiro nacional e } \\
\text { internacional. }\end{array}$ & $\begin{array}{l}\text { Controle e execução } \\
\text { financeira dos processos em } \\
\text { moeda nacional e estrangeira; } \\
\text { executar: análise da } \\
\text { concessão de crédito a } \\
\text { cliente; efetuar cobrança da } \\
\text { atividade-fim; elaborar fluxo } \\
\text { de caixa; e repasses } \\
\text { financeiros em moeda } \\
\text { nacional e estrangeira. }\end{array}$ \\
\hline
\end{tabular}

Fonte: Adaptada de Figueiredo (2001)

\subsection{Fontes de acumulação de capacidade não tecnológica}

As fontes para acumular capacidades, na visão de Penrose (1959), são estabelecidas com o processo de aprendizagem, que ocorrem de duas maneiras, um tipo pode ser formalmente ensinado, aprendido de outras pessoas ou de palavras escritas, e pode ser necessário expressar e transmitir esse aprendizado. O outro tipo se dá no armazenamento de aprendizado na forma de experiência pessoal. Assim, o conhecimento acumulado dentro da firma é transferido para o indivíduo, que ganha conhecimento e habilidade, provocando uma mudança na qualidade das rotinas executadas e no exercício de desenvolver habilidades para usar conhecimento acumulado dentro da firma, proporcionando uma mudança na qualidade ou atributo no nível organizacional (desenvolvimento de 
capacidades específicas à firma), assim a empresa passa a ter uma coleção de recursos produtivos, incluindo os recursos humanos.

Segundo Pavitt (1991), na aprendizagem pela experiência, uma vez que o conhecimento acumulado é, em parte, tácito, as tarefas, para as quais tal conhecimento é aplicado, são complexas e levemente estruturadas, ocorrendo uma forma de comunicação mais efetiva e frequente, e proporcionando o contato pessoal e as discussões. Dosi (1997) destaca que o aprendizado é um processo pelo qual a repetição e a experimentação capacitam as tarefas para que elas sejam desempenhadas com melhorias e mais rapidamente, podendo ser identificadas novas oportunidades produtivas. $\mathrm{O}$ autor contribuiu para a literatura ao enfatizar que o aprendizado tem várias características-chave: cumulatividade (o que é aprendido em um período se constrói sobre o que foi aprendido no período inicial); fenômeno coletivo e social (o aprendizado envolve habilidades muito mais organizacionais do que individuais); e ele requer códigos comuns e procedimentos coordenados e de comunicação.

Um dos recursos mais importantes para a criação de capacidade é o conhecimento organizacional, por meio do conhecimento existente, as empresas podem alcançar novos padrões em suas atividades, rotinas e tarefas, escolher novos focos estratégicos e continuamente se adaptar e criar suas capacidades dinâmicas (Tecce, Pisano, \& Shuen, 1997). Os pesquisadores Tacla e Figueiredo (2003) destacam a importância da captação de conhecimento para que as empresas criem e mantenham suas capacidades tecnológicas e organizacionais como recursos fundamentais à competição no mercado mundial. Dessa forma, para as empresas tornarem-se competitivas e alcançarem as empresas líderes, elas têm primeiro que adquirir conhecimento para criar e acumular suas próprias capacidades, engajando-se num processo de aprendizagem tecnológica e organizacional. Figueiredo (2003) aborda que o modo da trajetória e da velocidade de acumulação de capacidades organizacionais está, fortemente, associado à gestão dos vários processos de aprendizagem nas empresas ao longo do tempo.

Para mensurar os mecanismos de aprendizagem em gestão financeira, exibe o modelo de análise (Tabela 2) dos vários processos de aprendizagem, proporcionando identificar a forma de aquisição de conhecimentos técnicos, e, ainda, reproduz as características-chave dos diferentes mecanismos dos processos subjacentes de aprendizagem na empresa. $\mathrm{O}$ exame à luz do modelo contribuiu para explicar de que modo os níveis de capacidade não tecnológica foram estimulados pelos processos subjacentes de aprendizagem nos serviços básicos financeiros da Petrobras.

Revista de Administração e Inovação, São Paulo, v. 10, n.2, p.45-80, abr./jun. 2013. 
Tabela 2: Processos subjacentes de aprendizagem

\begin{tabular}{|c|c|c|c|c|}
\hline \multirow{3}{*}{$\begin{array}{l}\text { Processo de } \\
\text { Aprendiragem }\end{array}$} & \multicolumn{4}{|c|}{ Caracteristicas-chave dos processos subjacentes de aprentizagem } \\
\hline & Variedade & Intensidade & Funcionamento & Interaçăo \\
\hline & $\begin{array}{c}\text { Ausent-Presente } \\
\text { (Limitada-Moderada- } \\
\text { Diversa) }\end{array}$ & $\begin{array}{c}\text { Baixa-Intemitente- } \\
\text { Contíma }\end{array}$ & Rum-Moderado-Amplo & Fraca-Moderado-Forte \\
\hline \multicolumn{5}{|c|}{ PROCESSOS E MECANISMOS DE AQUISIÇĂO DE CONHECIMIENTO } \\
\hline $\begin{array}{l}\text { Aquisiçằ } \\
\text { Extema de } \\
\text { Conhecimento }\end{array}$ & $\begin{array}{l}\text { Presençalausência de } \\
\text { processos para adquirir } \\
\text { conhecimerto localmerte } \\
\text { ou no exterior. }\end{array}$ & $\begin{array}{l}\text { Modo oomo a errquesausa } \\
\text { este pocesso a brep do } \\
\text { termo, pode ser contrino, } \\
\text { intemiterte, ou ocomer uma } \\
\text { única vez }\end{array}$ & $\begin{array}{l}\text { Modo oomo o prooesso foi } \\
\text { criado e modo como ele opera } \\
\text { ao bmgo do termo. }\end{array}$ & $\begin{array}{l}\text { Modo como um processo } \\
\text { influência outro processo } \\
\text { de aquisiçăo extema oul } \\
\text { intema de conhecimento } \\
\text { elou processos de } \\
\text { comversão de } \\
\text { comhecimento. }\end{array}$ \\
\hline $\begin{array}{l}\text { Aquisiçăo } \\
\text { Interna de } \\
\text { Conhecimento }\end{array}$ & $\begin{array}{l}\text { Presençalausência de } \\
\text { processos para adquirir } \\
\text { comhecimerto farrendo } \\
\text { atividades internas. Essas } \\
\text { atividades podem ser de } \\
\text { rotina ou inovadoras }\end{array}$ & $\begin{array}{l}\text { Modo oomo a erpresausa } \\
\text { diferentes proossos para } \\
\text { aquisição intema de } \\
\text { combecimento. }\end{array}$ & $\begin{array}{l}\text { Modo como o proosso foi } \\
\text { criado, e modo como ele opera } \\
\text { ao bugo do termo tem } \\
\text { implicagoses práticas para } \\
\text { variedade e intensidade. }\end{array}$ & $\begin{array}{l}\text { Prooesso de oorhecimento } \\
\text { intemo pode ser } \\
\text { influenciado por processo } \\
\text { de aquisição extema. Pode } \\
\text { influenciar processos de } \\
\text { comversäo de } \\
\text { comhecimerto. }\end{array}$ \\
\hline \multicolumn{5}{|c|}{ PROCESSOS E MECAHISMOS DE COHVERSÃO DE COHHECIMENTO } \\
\hline $\begin{array}{l}\text { Codificaçăo de } \\
\text { Conhecimento }\end{array}$ & $\begin{array}{l}\text { Presençalausência de } \\
\text { diferentes proossos e } \\
\text { mecamismos para codificar } \\
\text { o combecinerto tácito. }\end{array}$ & $\begin{array}{l}\text { O modo oomo proossos de } \\
\text { padronização das operaçoses é } \\
\text { repetidamente feito. } \\
\text { Codificą̧ão auserte elou } \\
\text { irtemitente pode limitar a } \\
\text { aprendizagem organizacional. }\end{array}$ & $\begin{array}{l}\text { Modo oomo a oodificaçã do } \\
\text { combecimento foi criada e } \\
\text { opera a bro do tempo. Tem } \\
\text { implicaposes para } \\
\text { funcionamerto de todo o } \\
\text { processo de corversão de } \\
\text { combecimento. }\end{array}$ & $\begin{array}{l}\text { Modo oomo a oodificação } \\
\text { de comhecimento foi } \\
\text { influenciada por processos } \\
\text { de aquisição de comheoe- } \\
\text { mento ou por prooessos de } \\
\text { socialização de } \\
\text { combecimerto. }\end{array}$ \\
\hline $\begin{array}{l}\text { Socializaçăo de } \\
\text { Conhecimento }\end{array}$ & $\begin{array}{l}\text { Presençalausência de } \\
\text { diferentes processos através } \\
\text { dos quais indivíduos } \\
\text { compartilham seu } \\
\text { combecmento tácito. }\end{array}$ & $\begin{array}{l}\text { Modo como processos } \\
\text { prosseguem ao longo dos } \\
\text { anos. Irtensidade contrinua do } \\
\text { processo de socialização de } \\
\text { conhecimento pode } \\
\text { infhenciar codificação de } \\
\text { comhecimento. }\end{array}$ & $\begin{array}{l}\text { Modo como mecanismos de } \\
\text { socialização de conhecimento } \\
\text { foram criados e operam ao } \\
\text { lonep do tempo. Tem } \\
\text { implicaços para a variedade e } \\
\text { intensidade do prooesso de } \\
\text { conversão de conhecimento. }\end{array}$ & $\begin{array}{l}\text { Condução de diferentes } \\
\text { comhece-mentos tácitos } \\
\text { para um sistema efetivo. } \\
\text { Socializaçäo pode ser } \\
\text { influenciada por processos } \\
\text { de aquisição extema e } \\
\text { intema de comhecimerto. }\end{array}$ \\
\hline
\end{tabular}

Fonte: Adaptada de Figueiredo (2001)

Nessa perspectiva, neste artigo, os processos subjacentes de aprendizagem são analisados conforme a estrutura analítica desenvolvida por Figueiredo $(2001,2003)$, que permite examinar as implicações das práticas dos processos subjacentes de aprendizagem para a acumulação de capacidade tecnológica e organizacional (rotineira e inovadora) em empresas de setores industriais.

\section{DESENHO E MÉTODO DO ESTUDO}

Este artigo buscou analisar o desenvolvimento de capacidades não tecnológicas e o papel dos processos subjacentes de aprendizagem no âmbito da gestão financeira da indústria de petróleo estatal no Brasil, no período de 1957 a 2007, examinando sob a perspectiva da intensa geração de inovação tecnológica da indústria, a fim de verificar a evolução de capacidades específicas nos aspectos de apoiar o fluxo contínuo de exploração e produção de petróleo a partir da geração de inovação 
tecnológica. Os dados foram do tipo qualitativo, os quais serviram para fundamentar a análise para a verificação do desenvolvimento de capacidades em gestão financeira, já que o fluxo de processo tecnológico requer a forte presença de recursos financeiros; assim, propositalmente, foram tomadas áreas financeiras essenciais à trajetória de acumulação tecnológica da indústria.

Para conduzir a pesquisa do desenvolvimento de capacidades acumuladas a partir das ocorrências dos processos subjacentes de aprendizagem, derivou-se do modelo desenvolvido originalmente por Lall (1992), e Bell e Pavitt (1995), adaptado por Figueiredo (2001), que proporciona determinar com êxito a evolução dos níveis de capacidades específicas em gestão financeira pela indústria ao longo do período, segundo a Tabela 1. Nesse modelo, o desenvolvimento de capacidades não tecnológicas é analisado nas funções não tecnológicas e na sucessão de seus processos financeiros no fluxo produtivo da indústria, consequentemente, determinando o avanço de níveis de categorias de atividades simples para as mais complexas.

Desse modo, o artigo baseou-se em evidências empíricas colhidas a partir de extenso trabalho de campo, na busca de explicação para a temática proposta (Yin, 2005). Para tanto, utilizou-se de entrevistas com perguntas elaboradas para os diversos níveis de pessoas entrevistadas na indústria, obtendo-se respostas e informações genuínas. Também contribuíram as evidências secundárias, obtidas por meio de consulta aos arquivos históricos, aos documentos e às publicações da indústria.

\section{CONSTRUÇÃO E DESENVOLVIMENTO DE CAPACIDADES NÃO TECNOLÓGICAS EM GESTÃo FINANCEIRA PELA PETROBRAS}

Expõe-se o exame do desenvolvimento de capacidades não tecnológicas pela Petrobras na atividade de gestão financeira ao longo do período 1957-2007. O ponto de convergência da função não tecnológica da gestão de captação de financiamentos da Petrobras está voltado para planejar, decidir e acompanhar a modalidade de captação, bem como definir e acompanhar os limites de endividamento e estruturação financeira de projetos tecnológicos. Quanto à afluência da função não tecnológica de operações financeiras da Petrobras, a estrutura para relacionar-se com o mercado financeiro se dá por meio de mesa operacional com a finalidade de executar as operações financeiras de curto prazo no mercado interno e participar no mercado externo com operações financeiras. O foco principal da gestão do caixa da Petrobras está voltado para administrar no país e no exterior a disponibilidade de recursos financeiros da Petrobras e das empresas do sistema Petrobras, efetuar a

Revista de Administração e Inovação, São Paulo, v. 10, n.2, p.45-80, abr./jun. 2013. 
execução financeira de obrigações e direitos do sistema Petrobras e arrecadar a cobrança das atividades fins e não fins.

A Petrobras produziu, inicialmente, atividades financeiras elementares, mas procurou os meios para aplicar métodos e combinações financeiras à medida que eram requisitados novos investimentos no processo tecnológico da empresa, empenhando-se na criação de habilidades e competências ao longo do período de 1957 a 2007. Como consequência, passou a produzir processos financeiros inovadores, proporcionando que a Petrobras acumulasse capacidades não tecnológicas em gestão financeira, de modo a possibilitar acompanhar e apoiar a trajetória de acumulação de suas capacidades tecnológicas.

A Petrobras como um todo tem um viés de inovar em tecnológica, considerando, nesse contexto, a importância das atividades dos serviços financeiros essenciais na sua estrutura organizacional. O exame aponta que a aquisição de conhecimentos sempre foi um processo contínuo e amplamente utilizado na execução das atividades financeiras, possibilitando à gestão financeira da indústria expandir suas atividades além de suas fronteiras; com isso, estimulou a coordenação sistêmica em vários planos: organizacional e individual; e estratégico e operacional, requerendo o processo de inovação não tecnológica a combinação de diferentes habilidades e conhecimentos financeiros.

Dessa forma, sobre o desenvolvimento de capacidades não tecnológicas na Petrobras, relacionado à gestão financeira, a seção 5.1 apresenta o resultado e os detalhes da análise acerca dos avanços de tipos e níveis de capacidades não tecnológicas em gestão financeira pela Petrobras, no período de 1957 a 2007. A seção 5.2 mostra as fontes para o desenvolvimento de capacidades específicas identificadas na gestão financeira da indústria, que resultou no forte potencial de gerar inovação não tecnológica ao longo do período de análise.

\subsection{Desenvolvimento de capacidades não tecnológicas em gestão financeira}

Nesta seção, são apresentados os principais resultados do exame da construção e do desenvolvimento de capacidades não tecnológicas pela Petrobras em processos financeiros, divulgando os tipos e os níveis atingidos de capacidades específicas, com também é exposto o produto da análise em períodos, nas fases: a I (1957-1991) refere-se à construção e desenvolvimento de capacidades não tecnológicas; a II (1992-1997) reporta-se ao contínuo desenvolvimento de capacidades não tecnológicas; e a III (1998-2007) reconduz à evolução de capacidades não tecnológicas nas atividades produzidas pelos serviços básicos financeiros.

Revista de Administração e Inovação, São Paulo, v. 10, n.2, p.45-80, abr./jun. 2013. 
A base do modelo de avaliação das capacidades não tecnológicas está composta de seis níveis. Esse modelo foi utilizado para examinar as atividades desenvolvidas pelas três funções não tecnológicas: gestão de captação de financiamentos, operações de financeiras e gestão do caixa.

A representação da análise (Figura 2) indica a formação dos níveis 1, 2 e 3 (básico, básico renovado e intermediário superior), que se reportam à capacidade de executar atividades financeiras de rotinas utilizando métodos e operações financeiras disponibilizadas na estrutura organizacional da empresa e no mercado financeiro; em seguida, têm-se as estruturas para os níveis 4, 5 e 6 (superior, avançado e fronteira internacional), que se referem à capacidade de gerar melhorias contínuas nos processos financeiros e habilidades para produzir inovações nesses processos.

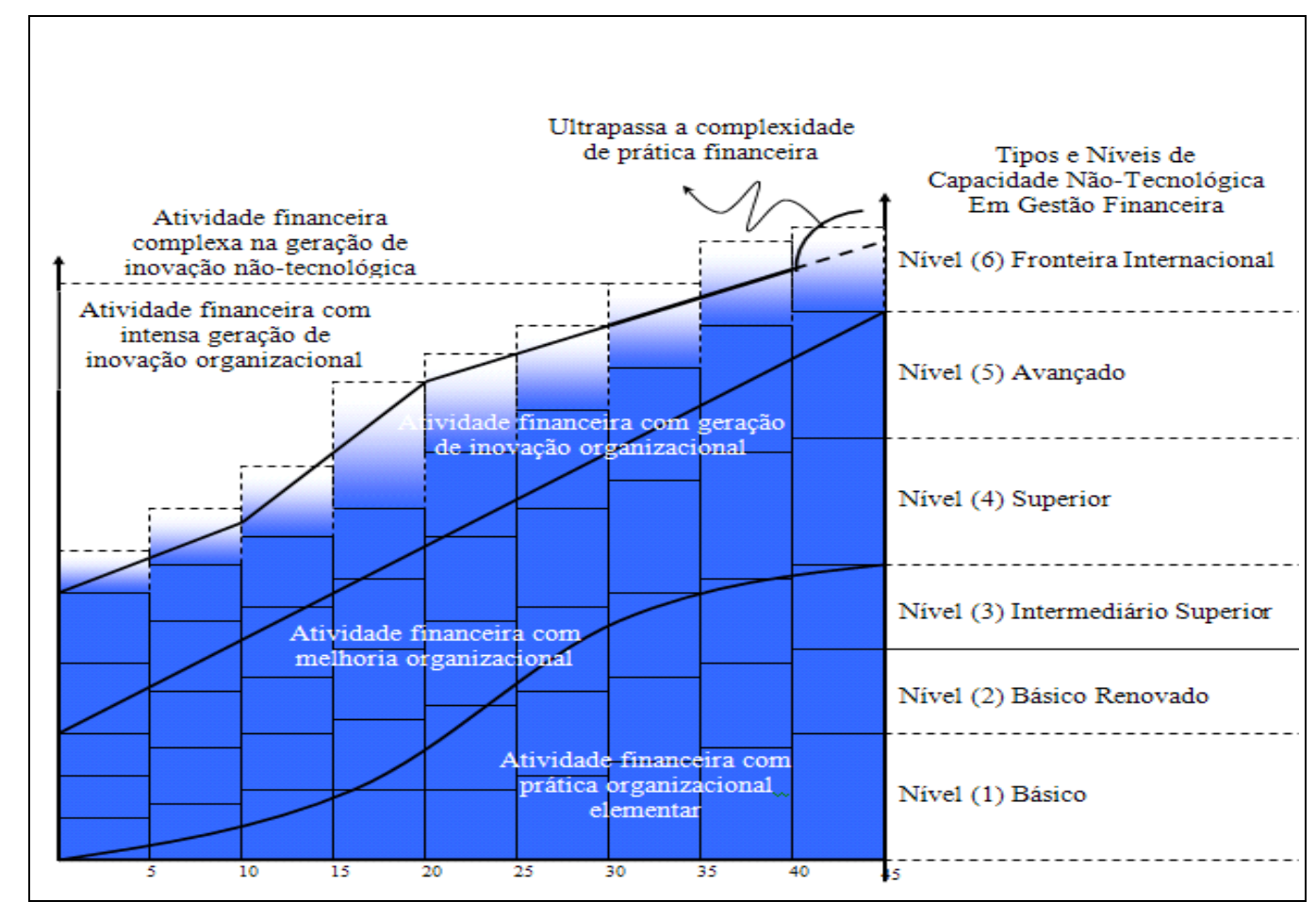

Figura 2: Níveis e tipos de capacidades não tecnológicas em gestão financeira

Fonte: Adaptada de Figueiredo (2001)

A gestão financeira da Petrobras acumulou plenamente capacidades não tecnológicas. Nas funções gestão de captação de financiamentos e operações financeiras, a Petrobras atingiu o nível 6 (fronteira internacional) e, na função gestão do caixa, a Petrobras alcançou o nível 5 (avançado). Esses níveis estão representados de forma resumida na Tabela 3.

Tabela 3: Níveis de capacidades não tecnológicas (1957-2007)

Revista de Administração e Inovação, São Paulo, v. 10, n.2, p.45-80, abr./jun. 2013. 


\begin{tabular}{|c|c|c|c|c|}
\hline Atividades & Níveis de Capacidade & $\begin{array}{c}\text { Captação de } \\
\text { Financiamentos }\end{array}$ & $\begin{array}{c}\text { Operações } \\
\text { Financeiras }\end{array}$ & $\begin{array}{c}\text { Gestão do } \\
\text { Caixa }\end{array}$ \\
\hline \multirow{3}{*}{ 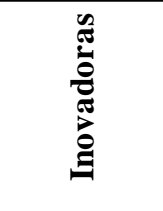 } & 6 - Fronteira Internacional & Atingiu & Atingiu & Não Atingiu \\
\hline & 5 - Avançado & Atingiu & Atingiu & Atingiu \\
\hline & 4 - Superior & Atingiu & Atingiu & Atingiu \\
\hline \multirow{3}{*}{ 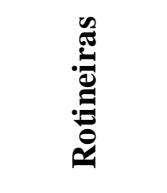 } & 3 - Intermediário Superior & Atingiu & Atingiu & Atingiu \\
\hline & 2 - Básico Renovado & Atingiu & Atingiu & Atingiu \\
\hline & 1 - Básico & Atingiu & Atingiu & Atingiu \\
\hline
\end{tabular}

Fonte: Derivada de pesquisa de campo

De um modo geral, as capacidades inovadoras em gestão financeira, na Petrobras, foram construídas e desenvolvidas de forma contínua nas fases I (1957-1991), II (1992-1997) e III (19982007). A partir das evidências, é possível perceber diversas modificações organizacionais na estrutura interna da gestão financeira, ligadas à diversidade de processos financeiros produzidos com melhorias organizacionais e inovadoras. Esses efeitos estão amparados desde as correntes mudanças organizacionais relacionadas à aquisição de tecnologias de países industrializados até a robustez da propriedade tecnológica da Petrobras. Nesse ambiente de intensa sinergia, a gestão financeira precisou exercer estratégias inovadoras para atender às necessidades do fluxo produtivo, ou seja, foram requeridas da Petrobras práticas financeiras sofisticadas para acompanhar o processo de desenvolvimento tecnológico.

\subsection{Tipos e níveis de capacidades não tecnológicas em gestão financeira}

De acordo com o modelo que (exemplificado na Tabela 1) analisa o curso de construção e desenvolvimento de capacidades específicas, é possível expor o intenso exercício das complexas atividades financeiras na captura de tipos e níveis de capacidades não tecnológicas pela Petrobras. A Figura 3 demonstra o movimento dos tipos e dos níveis alcançados para acumular capacidades não tecnológicas em gestão financeira pela Petrobras.

Por meio das características do modelo adaptado, pode-se identificar a natureza e os níveis conquistados de capacidades não tecnológicas pela Petrobras em gestão financeira, como, também, observar o tempo que levou para mover-se do nível básico até os níveis mais elevados; o que significa que a Petrobras teve uma trajetória ascendente de capacidades inovadoras distintas, em particular não tecnológicas, ao longo das fases examinadas (1957-2007).

Revista de Administração e Inovação, São Paulo, v. 10, n.2, p.45-80, abr./jun. 2013. 


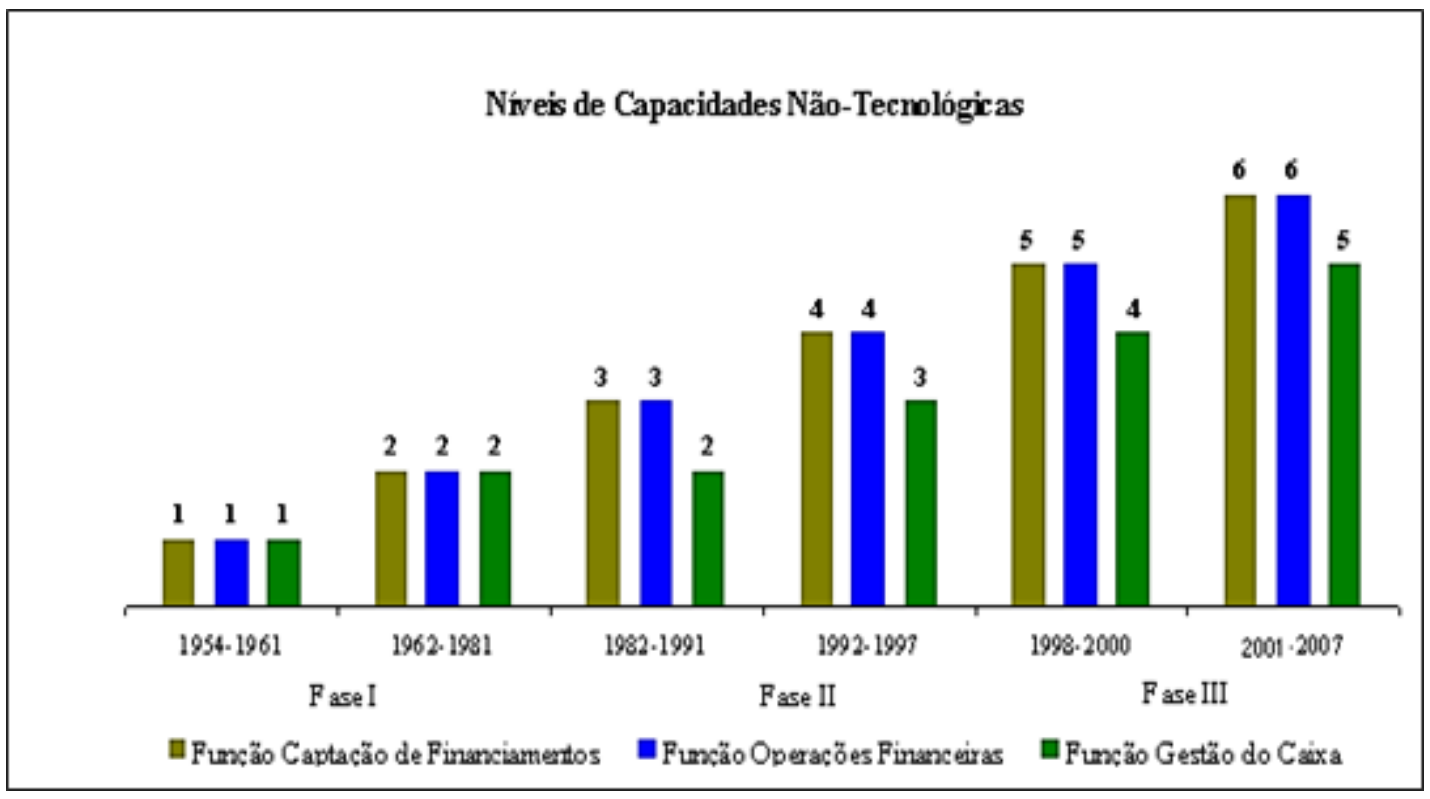

Figura 3: Nível de acumulação de capacidades não tecnológicas em gestão financeira (1957-2007)

Fonte: Derivada de pesquisa de campo

A partir do exame da fase I (1957-1991), nota-se que a função não tecnológica gestão da captação de financiamentos desenvolveu atividades básicas e moveu-se para executar rotinas financeiras mais elevadas, acompanhando o fluxo produtivo da Petrobras; conquistando: N(1) básico $\rightarrow \mathrm{N}(2)$ básico renovado $\rightarrow \mathrm{N}(3)$ intermediário superior $\rightarrow \mathrm{N}(4)$ superior, acumulando, assim, capacidades para criar inovação no final dessa fase. Percebe-se que, com a análise da função não tecnológica operações financeira, na fase I (1957-1991), foram consolidadas capacidades básicas, mas com melhorias nas rotinas financeiras, procurando prosperar com novas estratégias no fortalecimento dos processos financeiros; avançou do $\mathrm{N}(1)$ básico $\rightarrow \mathrm{N}(2) \rightarrow$ básico renovado $\rightarrow \mathrm{N}(3)$ intermediário superior. A busca por competências foi intensa pela função não tecnológica gestão do caixa, na fase I (1957-1991), porém as atividades financeiras ficaram confinadas a executar rotinas com limitação de criatividade, movendo-se do N(1) básico $\rightarrow \mathrm{N}(2)$ básico renovado.

Na fase II (1992-1997), para as atividades financeiras da função não tecnológica operações financeiras foram requeridas capacidades específicas para desenvolver atividades com um grau superior de complexidade, o que levou a avançar para o N(4) superior, evoluindo na acumulação de capacidades não tecnológicas. Entretanto, as demais funções não tecnológicas mantiveram-se estagnadas, ou seja, não se moveram para mais níveis elevados.

$\mathrm{Na}$ fase III (1998-2007), as funções não tecnológicas da captação de financiamentos $e$ operações financeiras moveram-se para o $\mathrm{N}(5)$ avançado, produzindo atividades financeiras inovadoras, e, rapidamente, ambas as funções não tecnológicas acompanharam a dinâmica do setor 
produtivo e seguiram em direção ao N(6) fronteira internacional, desenvolvendo atividades financeiras inovadoras. Quanto à função não tecnológica gestão do caixa, nessa fase, foi priorizada a busca por habilidades e esforçou-se para produzir atividades com melhorias significativas e capacidades específicas, de modo a executar atividades financeiras mais complexas e acompanhar as estratégias tecnológicas da Petrobras. A Petrobras buscou níveis elevados de capacidades específicas para a função gestão do caixa, fornecendo sistemas técnico-físicos (máquinas, softwares, banco de dados). Logo, a interação das atividades da função não tecnológica conquistou o $\mathrm{N}(3)$ intermediário superior, mobilizando, no final do período, forças para produzir atividades financeiras inovadoras, o que motivou a avançar para o N(4) superior, conquistando imediatamente o N(5) avançado, ao desenvolver atividades inovadoras até 2007.

\subsection{Trajetória da acumulação de capacidades não tecnológicas}

$\mathrm{Na}$ análise dos resultados obtidos do desenvolvimento de capacidades não tecnológicas, é possível identificar o tempo em que a gestão financeira levou para acumular níveis de capacidades específicas para acompanhar o complexo fluxo produtivo, bem como as ações que permitiram movimentar-se para os $\mathrm{N}(1) \rightarrow \mathrm{N}(2) \rightarrow \mathrm{N}(3) \rightarrow \mathrm{N}(4) \rightarrow \mathrm{N}(5)$ e alcançar o nível $\mathrm{N}(6)$, ou seja, nível absoluto de capacidades não tecnológicas acumuladas pela Petrobras; equiparando suas capacidades específicas (gestão financeira), ao longo do período de 1957 a 2007, às de empresas industrializadas acima da fronteira tecnológica internacional.

Os níveis de capacidades específicas, identificados pela análise, foram conquistados, na fase I (1957-1991), pelas funções não tecnológicas com movimentos lentos. De acordo com as evidências, a limitação de recursos organizacionais para execução das atividades dos serviços básicos financeiros contribuiu para os movimentos debilitados, dificultando para a Petrobras obter capacidades específicas de modo mais dinâmico. Por isso, a função não tecnológica gestão da captação de financiamentos levou 24 anos, ao longo do período de 1957 a 1981, para mover-se do N(1) básico $\rightarrow \mathrm{N}(2)$ básico renovado. Por sua vez, a função expandiu suas capacidades específicas ao avançar para o N(3) intermediário superior, em 8 anos no período de 1981 a 1990; e conquistou o nível N(4) superior, em 1 ano no período de 1990 a 1991. Os dados mostram que os serviços básicos organizacionais da indústria geraram capacidades próprias, embora não tecnológicas, por perceber influências das estratégias tecnológicas das atividades industriais. A função não tecnológica de operações financeiras alcançou o N(2) básico renovado após 24 anos para acumular as primeiras capacidades básicas, embora revigoradas no período de 1957 a 1981; e buscou novas alternativas para

Revista de Administração e Inovação, São Paulo, v. 10, n.2, p.45-80, abr./jun. 2013. 
criar capacidades específicas, movimentando-se para o N(3) intermediário superior após 10 anos, no período de 1981 a 1991. O desenvolvimento de capacidades não tecnológicas da função não tecnológica gestão do caixa foi diverso das demais funções não tecnológicas analisadas, o que foi ocasionado pela sua permanência no N(1) básico por 34 anos, executando rotinas básicas, ao longo do período de 1957 a 1991; muito embora houvesse a limitação de desenvolver capacidades específicas de modo homogêneo com as demais funções por executar rotinas financeiras de modo elementar.

Na fase II (1992-1997), a função não tecnológica operações financeiras destacou-se ao conquistar o N(4) superior, levando 10 anos para acumular capacidades não tecnológicas no período.

A partir das evidências, é possível observar que a Petrobras procurou buscar, na fase II (19921997), esforços para adquirir os recursos organizacionais, ou seja, ferramentas de execução financeira e controles gerenciais (TI), como também energia para adaptação das atividades dos serviços básicos financeiros; com isso, a estrutura organizacional interna da gestão financeira foi afetada de maneira considerável, introduzindo a administração centralizada e buscando fluidez e racionalidade no desenvolvimento organizacional dos serviços organizacionais básicos da empresa. Esse período, também, foi marcado pela estagnação da empresa, em virtude de fatos de origem externa que produziram efeitos em seus processos organizacionais.

Na fase III (1998-2007), foi identificado que fatores de origem externa à Petrobras exigiram mudanças na sua estrutura organizacional, afetando de maneira considerável os serviços básicos financeiros com a implantação de melhorias organizacionais. A função não tecnológica gestão de captação de financiamento levou 8 anos para atingir o $\mathrm{N}(5)$ avançado desenvolvendo atividades inovadoras, no período de 1991 a 1999; rapidamente, alcançou o N(6) fronteira internacional, movendo-se em 1 ano, no período de 1999 a 2000, produzindo estratégias financeiras inovadoras e acumulando capacidades não tecnológicas por utilizar processos financeiros inovadores. Semelhante trajetória foi a da função não tecnológica operações financeiras, que acumulou capacidades para produzir inovações por movimentar-se rapidamente para o $\mathrm{N}(5)$ avançado, utilizando-se de inovações nos seus processos financeiros, com isso, levou 2 anos para acumular capacidades inovadoras, no período de 1997 a 1999; avançou para o N(6) na fronteira internacional, acumulando capacidades não tecnológicas em 1 ano, no período de 1999 a 2000.

Nessa fase, a Petrobras priorizou a função não tecnológica gestão do caixa, buscando os meios para evoluir as capacidades específicas da função na produção de rotinas financeiras com melhorias organizacionais, levando 13 anos para alcançar o N(3) intermediário superior, no período de 1991 a 2004. Em 2 anos foi possível conquistar o N(4) superior, introduzindo atividades inovadoras, no período de 2004 a 2006; com bases organizacionais (recursos) mais fortalecidas, em 1 ano, 
movimentou-se para o $\mathrm{N}(5)$ avançado, desenvolvendo atividades inovadoras no período de 2006 a 2007.

Penrose (1959) destaca em sua abordagem que a direção geral da inovação na firma (incluindo inovação na produção) não é casual, mas está fortemente relacionada à natureza dos recursos existentes (incluindo capital-equipamento) e ao tipo e gama de serviços produtivos e organizacionais que eles podem render. Com base nessa ideia, Teece, Pisano e Shuen (1997) apontam que a criação de riqueza, em regimes de mudança comercial e operacional, depende muito de ajustes tecnológicos internos, organizacionais.

\section{FONTES PARA DESENVOLVIMENTO DE CAPACIDADES NÃO TECNOLÓGICAS EM GESTÃO FINANCEIRA PELA PETROBRAS}

Nesta seção, são apresentados os principais resultados das fontes identificadas na análise para o desenvolvimento de capacidades não tecnológicas, em particular gestão financeira, pela Petrobras, ao longo do período de 1957 a 2007. O modelo de análise mostrou, na fase I (1957-1991), a competência básica em gestão financeira pela Petrobras, o seu acesso contínuo ao conhecimento externo e a utilização desse conhecimento. Eficientemente, pôde a Petrobras desenvolver mecanismos de conhecimento interno e a conversão de conhecimentos na estrutura organizacional dos serviços básicos financeiros, o que também permitiu a execução de processos financeiros com melhorias nessa fase. Nas fases II (1992-1997) e III (199-2007), o conhecimento e a aprendizagem desenvolveram-se cumulativamente, cabendo à Petrobras acumular capacidades não tecnológicas em gestão financeira na fronteira não tecnológica internacional.

\subsection{Mecanismo de aquisição externa de conhecimento}

Os mecanismos de aquisição externa de conhecimentos foram sistemicamente operantes ao longo da análise das atividades da gestão financeira. $\mathrm{O}$ modelo de análise proposto (Tabela 2) encontrou evidências (Tabela 4) da sólida presença dos processos de aquisição de conhecimento externo durante todas as fases pesquisadas, assim foi possível identificar as características-chave dos processos subjacentes de aprendizagem na Petrobras, apontando a variedade, a intensidade de modo contínuo e o funcionamento amplo.

Tabela 4: Mecanismos de aquisição externa de conhecimento (1957-2007)

Revista de Administração e Inovação, São Paulo, v. 10, n.2, p.45-80, abr./jun. 2013. 


\begin{tabular}{|c|c|c|c|}
\hline \multirow{2}{*}{ Mecanismos de aprendizagem } & \multicolumn{3}{|c|}{ Presença ou ausência } \\
\hline & 957-1991 & 992-1997 & 998-2007 \\
\hline $\begin{array}{l}\text { ição externa de conhecimento } \\
\text { tratação de especialistas e técnicos } \\
\text { ialistas e técnicos de órgãos públicos } \\
\text { os e especialistas do mercado de trabalho } \\
\text { lttoria financeira } \\
\text { inamento externo } \\
\text { amentos especializados em finanças (graduação, pós-graduação e } \\
\text { ado) } \\
\text { amento especializado em finanças curta duração } \\
\text { ama de desenvolvimento gerencial } \\
\text { Interação com bancos, órgãos públicos, clientes, } \\
\text { edores e parceiros } \\
\quad \text { Interação com negociações financeiras } \\
\text { Integração para desenvolvimento de projetos }\end{array}$ & $\begin{array}{l}\text { Presente } \\
\text { Presente } \\
\text { Presente } \\
\\
\text { Presente } \\
\text { Presente } \\
\text { Presente }\end{array}$ & $\begin{array}{l} \\
\text { presente } \\
\text { presente } \\
\text { presente }\end{array}$ & $\begin{array}{l}\text { Presente } \\
\text { Presente } \\
\text { presente }\end{array}$ \\
\hline
\end{tabular}

Fonte: Derivada da pesquisa de campo

Nos anos iniciais da fase I (1954-1991), os recursos humanos com conhecimento em gestão financeira foram disponibilizados por diversos órgãos públicos federais para a Petrobras, entre eles especialistas e técnicos com conhecimentos em processos financeiros. Ainda, visando a construir e a fortalecer suas bases de habilidade na atividade financeira, coube à Petrobras contratar os serviços externos de empresas no mercado nacional e internacional, a fim de assessorar suas demandas financeiras e, ao mesmo tempo, criar uma forma de propagar esse conhecimento na estrutura organizacional da gestão financeira. Durante a década de 1960, a Petrobras, ainda, sentia a necessidade de contratar especialistas e técnicos em finanças, constantemente selecionava no mercado a aquisição de conhecimento externo.

Outra forma de aquisição de conhecimento externo apontado na análise foi a busca da formação de especialistas e técnicos próprios em gestão financeira. A Petrobras tratou de realizar convênio com instituições de ensino superior nacional, disponibilizando cursos de graduação, pósgraduação e mestrado, de modo que a estratégia de capacitação da equipe da gestão financeira auxiliou a sua evolução tecnológica. Por sua vez, em relação ao domínio dos processos de aprendizagem, consensualmente reconhecido na análise, também foi identificada a formação de equipes especializadas distinguidas pela execução das atividades financeiras da Petrobras, o que, constantemente, ocasionava as reestruturações organizacionais na área financeira, tais alterações ocorreram com base nos conhecimentos adquiridos ao longo da fase I (1957-1991).

Na fase II (1992-1997), a estratégia de aquisição externa de conhecimentos foi mantida, mas de modo mais a atender às atividades específicas de financiamentos. Os treinamentos externos nessa fase foram identificados, mas com movimentos estratégicos diferenciados da fase I (1957-1991). Os 
colaboradores, ao retornarem dos processos de aprendizagem externa, passaram a ser direcionados para multiplicar esses conhecimentos aos demais colaboradores da gestão financeira.

Na fase III (1998-2007), a Petrobras, como estava seguindo em direção da globalização financeira pela sua integração aos mercados financeiros internacionais, necessitou incorporar novos conhecimentos para lidar com investidores internacionais e para executar operações financeiras inovadoras. A estratégia da Petrobras foi enviar especialistas para capacitação no exterior, desse modo pôde formar uma rede articulada de conhecimentos nos fluxos financeiros. Não obstante, acumulou esforços para contratar consultores externos para acelerar o processo de aprendizagem; coube, também, a contratação de especialistas e técnicos para o seu quadro de colaboradores com um novo modelo de capacitação.

\subsection{Mecanismo de aquisição interna de conhecimento}

A partir dos dados coletados, foi possível identificar que os mecanismos de aquisição interna de conhecimentos utilizados (Tabela 5) em gestão financeira pela Petrobras estavam presentes com variedade diversa, e a sua utilização era de forma intensa e contínua. Esses mecanismos contaram também com um funcionamento amplo, à luz do modelo de análise proposto (Tabela 2).

Tabela 5: Mecanismos de aquisição interna de conhecimento (1957-2007)

\begin{tabular}{|c|c|c|c|}
\hline \multirow{2}{*}{ Mecanismos de aprendizagem } & \multicolumn{3}{|c|}{ Presença ou ausência de mecanismos } \\
\hline & 1957-1991 & 1992-1997 & 1998-2007 \\
\hline $\begin{array}{l}\text { Aquisição interna de conhecimento } \\
\text { 1. Treinamento interno pela empresa } \\
\text { Treinamento interno em práticas financeiras } \\
\text { Treinamento interno utilização de sistemas } \\
\text { Treinamento interno engenharia financeira } \\
\text { 2. Seminário interno área financeira } \\
\text { Apresentação de trabalhos e projetos financeiros por } \\
\text { especialistas e técnicos } \\
\text { 3. Atividades de rotina, mecanismo aprendendo-fazendo } \\
\text { Participação de funcionários contratados } \\
\text { Participação em grupos de trabalho } \\
\text { Participação de especialistas em projetos no exterior }\end{array}$ & $\begin{array}{l}\text { Presente } \\
\text { Ausente } \\
\text { Presente } \\
\text { Presente } \\
\\
\text { Presente } \\
\text { Presente } \\
\text { Presente }\end{array}$ & $\begin{array}{l}\text { Presente } \\
\text { Presente } \\
\text { Presente } \\
\text { Presente } \\
\\
\text { Presente } \\
\text { Presente } \\
\text { Presente }\end{array}$ & $\begin{array}{l}\text { Presente } \\
\text { Presente } \\
\text { Presente } \\
\text { Presente } \\
\\
\text { Presente } \\
\text { Presente } \\
\text { Presente }\end{array}$ \\
\hline
\end{tabular}

Fonte: Derivada da pesquisa de campo

Na fase I (1957-1991), a Petrobras fez uso, desde o início de suas atividades em gestão financeira, dos processos de treinamento interno através da orientação e supervisão da execução das rotinas pelos especialistas e técnicos cedidos dos órgãos públicos federais, com total sinergia entre o quadro de colaboradores contratados. Esse mecanismo de aprendizagem foi refletido nas rotinas da gestão financeira, com a criação de complexos controles e conferências. Entretanto, as evidências 
apontaram que as rotinas de execução financeira foram efetuadas com o mínimo de recursos organizacionais nessa fase. Porém, havia a interação entre especialistas e técnicos recém-adquiridos com as equipes instaladas, caracterizando a socialização de conhecimentos.

Na fase II (1992-1998), a forma de capacitação interna ocorria por meio de treinamentos em workshops. No entanto, tinha um tratamento específico para as atividades não tecnológicas de captação e operações financeiras, como forma de incentivar o processo de aprendizagem e um meio de obter melhorias e inovações nos processos financeiros da Petrobras. Porém, a pesquisa apontou pouca participação dos processos de execução do caixa da Petrobras.

Na fase III (1998-2007), a Petrobras criou programas de capacitação para a área financeira junto à Universidade Corporativa, inaugurando um novo ciclo de formação de recursos humanos. Esses esforços tiveram como finalidade a capacitação da força de trabalho da gestão financeira, de modo a atender às necessidades de expansão seletiva da Petrobras, da gestão de negócios (Joint Venture), da integração com a cadeia produtiva e funções corporativas. A Petrobras implantou a prática de governança corporativa, por meio do Projeto Valor, que veio a intensificar a capacitação das equipes da área financeira, disponibilizando cursos internos voltados para gestão de processos, procedimentos e controles financeiros inovadores.

\subsection{Mecanismo de conversão do conhecimento}

O mecanismo de conversão de conhecimentos, em especial a socialização, proporcionou que a Petrobras formalizasse seus processos de aprendizagem em gestão financeira para apoiar e atender às demandas das funções tecnológicas da empresa.

Na fase I (1957-1991), o centro das atenções da Petrobras foi buscar e convencionar os recursos econômico-financeiros necessários a fim de transferir aos fornecedores de tecnologia importada pelo setor produtivo. O exame identificou, à luz do modelo analítico (Tabela 2), a variedade de mecanismos de aquisição de conhecimentos externos e internos, o que repercutiu a sua operacionalização nos mecanismos de conversão desses conhecimentos através da socialização de forma contínua, e suas funcionalidades foram amplas para formação de conhecimentos tácitos pelos recursos humanos da área financeira. Embora houvesse o mecanismo de conversão pela codificação de conhecimentos das rotinas em gestão financeira, não houve motivação para implantação, o que poderia ter contribuído para os mecanismos de aprendizagem em finanças. Nesse sentido, o conhecimento criado pelos indivíduos dentro da firma, de um lado, é incorporado neles próprios e o

Revista de Administração e Inovação, São Paulo, v. 10, n.2, p.45-80, abr./jun. 2013. 
conhecimento criado através de interações sociais, de outro, é incorporado no gerenciamento de uma "equipe de trabalho" (Penrose, 1959).

Na fase II (1992-1997), a Petrobras mobilizou-se para disponibilizar o conhecimento voltado para a operacionalização de um sistema de informação, repercutindo intensamente na construção de capacitação. As atividades de treinamento e o desenvolvimento dos recursos humanos foram efetuados de forma estratégica para atender às perspectivas globais da empresa; apesar da tentativa de conversão de conhecimentos na forma de codificação das rotinas financeiras, ainda, nessa fase, não foram intensificados os esforços necessários para implementar tal aprendizado.

Na fase III (1998-2007), intensificaram os mecanismos de aprendizagem das funções dos serviços básicos financeiros, com a cultura principal de especializar os técnicos e especialistas com conhecimentos avançados em finanças, inclusive com propagação para finanças internacionais, proporcionando o acesso da conversão na socialização de conhecimentos entre os especialistas e técnicos das rotinas financeiras. No final dessa fase, mobilizou-se a empresa para criar o mecanismo de codificação das rotinas financeiras e acelerar a aprendizagem no âmbito organizacional.

Diante do exposto, na Tabela 6, são apresentados os mecanismos de conversão de conhecimento ao longo das fases analisadas.

Tabela 6: Mecanismos de conversão de conhecimento (1957-2007)

\begin{tabular}{|c|c|c|c|}
\hline \multirow{2}{*}{ Mecanismos de conversão de aprendizagem } & \multicolumn{3}{|c|}{$\begin{array}{c}\text { Presença ou ausência de } \\
\text { mecanismos }\end{array}$} \\
\hline & $\begin{array}{l}1957- \\
1991 \\
\end{array}$ & $\begin{array}{c}1992- \\
1997\end{array}$ & $\begin{array}{c}\text { 1998- } \\
2007\end{array}$ \\
\hline $\begin{array}{l}\text { Socialização de conhecimento } \\
\text { 1.Desenvolvimentos de processos em conjunto com unidades operacionais } \\
\text { apoiadas } \\
\text { Interação para construção e projetos nos processos financeiros } \\
\text { Interação continuada dos processos construídos } \\
\text { 2. Solução compartilhada com problemas nos processos financeiros } \\
\text { Participação em grupos de trabalhos financeiros } \\
\text { Trabalhos em grupos para criação de novas rotinas e processos } \\
\text { Reuniões para soluções de procedimentos } \\
\text { Participação em grupos de melhorias e inovações nas rotinas } \\
\text { financeiras } \\
\text { finalização de processos financeiros } \\
\text { 3. Rotação no trabalho, grupos multidisciplinares } \\
\text { Equipe de trabalho multiplicador de conhecimento } \\
\text { Novos contratados executam rotinas sob supervisão de especialistas } \\
\text { 4. Sistema próprio para disseminação da informação } \\
\text { Compartilhamento de dados em rede } \\
\text { Comunicação formal por meio de CI } \\
\text { 5. Interação entre gestores e equipes }\end{array}$ & $\begin{array}{l}\text { Presente } \\
\text { Presente } \\
\text { Presente } \\
\text { Presente } \\
\text { Presente }\end{array}$ & $\begin{array}{l}\text { Presente } \\
\text { Presente } \\
\text { Presente } \\
\text { Presente } \\
\text { Presente }\end{array}$ & $\begin{array}{l}\text { Presente } \\
\text { Presente } \\
\text { Presente } \\
\text { Presente } \\
\text { Presente }\end{array}$ \\
\hline
\end{tabular}

Revista de Administração e Inovação, São Paulo, v. 10, n.2, p.45-80, abr./jun. 2013. 


\begin{tabular}{|c|c|c|c|}
\hline $\begin{array}{l}\text { Interação com a equipe de trabalho } \\
\text { Conhecimento da dificuldade das equipes } \\
\text { Comunicação entre as equipes de acertos e erros nas rotinas } \\
\text { financeiras }\end{array}$ & $\begin{array}{l}\text { Presente } \\
\text { Presente } \\
\text { Presente }\end{array}$ & $\begin{array}{l}\text { Presente } \\
\text { Presente } \\
\text { Presente }\end{array}$ & $\begin{array}{l}\text { Presente } \\
\text { Presente } \\
\text { Presente }\end{array}$ \\
\hline $\begin{array}{l}\text { Codificação de conhecimento } \\
\text { 1. Codificação e especificação dos processos financeiros } \\
\text { Codificação do padrão de processos financeiros } \\
\text { Desenvolvimento de atualização contínua } \\
\text { 2. Elaboração de procedimento das rotinas financeiras } \\
\quad \text { Regulamentos (comunicação interna e memorando) } \\
\text { Elaboração de procedimentos e instruções técnicas dos processos } \\
\text { financeiros } \\
\text { 3. Sistema de controles gerenciais e administrativos } \\
\text { Controle da documentação dos processos financeiros } \\
\text { Integração entre sistema operacional e corporativo }\end{array}$ & $\begin{array}{l}\text { Ausente } \\
\text { Ausente } \\
\text { Presente } \\
\text { Ausente }\end{array}$ & $\begin{array}{l}\text { Ausente } \\
\text { Ausente } \\
\text { Presente } \\
\text { Ausente }\end{array}$ & $\begin{array}{l}\text { Ausente } \\
\text { Ausente } \\
\text { Presente } \\
\text { Ausente }\end{array}$ \\
\hline
\end{tabular}

Fonte: Derivada de pesquisa de campo

Considerando a análise aqui empreendida, pode-se afirmar que a fonte de conhecimento em gestão financeira na Petrobras não reside no seu conjunto de recursos organizacionais (pessoal, equipamentos e TI), mas, sim, na forma como estes são usados, ou seja, na geração dos serviços organizacionais básicos disponibilizados, eficientemente, em toda a empresa.

\section{CONCLUSÃO}

Este artigo trouxe evidências empíricas sobre o desenvolvimento de capacidades não tecnológicas e o papel dos processos subjacentes de aprendizagem em gestão financeira pelas funções não tecnológicas gestão de captação de financiamentos, gestão de operações financeiras e gestão do caixa, ao longo do período de 1957 a 2007, na indústria de petróleo estatal brasileira.

O estudo identificou que, na fase I (1957-1991), a Petrobras iniciou produzindo capacidades básicas e renovadas em gestão financeira, proporcionando no final dessa fase capacidades para criar processos financeiros com melhorias e com perspectivas de produzir inovações. Essa movimentação está conjugada com os mecanismos de aprendizagem externa e interna e foi consolidada de forma

Revista de Administração e Inovação, São Paulo, v. 10, n.2, p.45-80, abr./jun. 2013. 
ampla e contida a ponto de fortalecer o desenvolvimento de atividades técnicas básicas e rotineiras com melhorias em gestão financeira.

A Petrobras, na fase II (1992-1997), caracterizou-se por produzir processos de gestão financeira com melhorias, movimentando-se de modo lento no desenvolvimento de capacidades inovadoras; entretanto, empenhou-se nos processos de aprendizagem para sustentar a utilização de novas ferramentas tecnológicas.

Na fase III (1998-2007), a indústria produziu inovações nos processos de gestão financeira, impulsionando-a a conquistar tipos e níveis de capacidades não tecnológicas absolutos à fronteira internacional de inovação não tecnológica, motivados pelas fontes de desenvolvimento dessas capacidades a ponto de acumulá-las ao longo do período analisado.

$\mathrm{O}$ estudo demonstrou que as fontes de aprendizagem influenciaram o desenvolvimento de inovações em gestão financeira pela Petrobras. A investigação identificou também que a aprendizagem por interação ocorreu por fontes internas e externas à empresa, e a busca por conhecimento baseou-se em dois diferentes propósitos, ou seja, buscar a especialização em gestão financeira; e o contínuo processo de aprendizagem motivou a Petrobras a buscar alternativas e soluções inovadoras em gestão financeira para o atendimento das demandas do seu fluxo produtivo. Portanto, a partir da análise realizada neste artigo, percebe-se que existem fortes possibilidades de acumulação de capacidades específicas e merecem realce as inovações desenvolvidas pelos serviços básicos organizacionais conduzidos por empresas no contexto de países em desenvolvimento.

Nesse contexto, o artigo apresentou a mensuração dos níveis de capacidades em gestão financeira da Petrobras, permitindo identificar e avaliar a dinâmica no contínuo espaço de tempo à luz dos modelos de análise propostos, que elucidaram o desenvolvimento e a trajetória de acumulação de capacidades não tecnológicas pela Petrobras, ao longo do período de 1957 a 2007, revelando essas capacidades de forma histórica que auxiliaram e apoiaram, com seus processos financeiros, a trajetória de acumulação da Petrobras.

\section{REFERÊNCIAS}

Ariffin, N. (2000). The internationalisation of innovative capabilities: the malaysian electronics industry. Thesis of Doctorate, SPRU, University of Sussex, Brighton.

Australian Bureau of Statistics (ABS) (1994). Australian Social Trends, 1994. Canberra: ABS.

Revista de Administração e Inovação, São Paulo, v. 10, n.2, p.45-80, abr./jun. 2013. 
Barañano, A. M. (2003). The non technological side of technological innovation: state of the art and guidelines for further empirical research. Int. J. Entrepreneurship and Innovation Management, $3(1 \mathrm{e}$ 2), 107-125.

Barañano, A. M. (2005). Gestão da inovação tecnológica: estudo de cinco PMEs portuguesas. Revista Brasileira de Inovação, 4(1), 57-96.

Bell, M. (1984). Learning and the accumulation of industrial technological capacity in developing countries. In K. King, \& M. Fransman (Eds.), Technological capability in the third world. London: Macmillan.

Bell, M., \& Pavitt, K. (1993). Technological accumulation and industrial growth: contrasts between developed and developing countries. Industrial and Corporate Change, 2, 157.

Bell, M., \& Pavitt, K. (1995). The development of technological capabilities. In I. Haque, M. Bell, C. Dahlman, S. Lall, \& K. Pavitt, Trade, technology and international competitiveness. Washington, DC: The World Bank.

Bessant, J. (1991). Managing advanced manufacturing technology. The challenge of the fifth wave. Oxford: Blackwell.

Chandler, A. D. (1962). Strategy and structure: chapters in the history of industrial enterprise. Cambridge, MA: MIT Press.

Dahlman, C., \& Fonseca, F. (1978). From technological dependence to technological development: the case of the Usiminas steel plant in Brazil. IBD/ECLA Research Programme, Working Paper 21, 1978.

Dahlman, C., Ross-Larsen, B., \& Westphal, L. E. (1987), Managing technological development: lessons from the newly industrializing countries. World Development, 6(15), 759-775.

Damanpour, F., Szabat, K. A., \& Evan, W. M. (1989). The relationships between types of innovation and organizational performance. Journal of Management Studies, 26(6), 587-601.

Dantas, E. (2006). The development of knowledge networks in latecomer innovation systems: The case of Petrobras in the Brazilian offshore oil industry. Thesis of Doctorate, Philosophy in Science and Technology Policy Research, University of Sussex, Brighton.

Dosi, G. (1997). Globalização, tecnologia \& desenvolvimento. Revista Rumos do Desenvolvimento, (143), 4-9.

Dutrénit, G. (2000). Learning and knowledge management in the firm: from knowledge accumulation to strategic capability. Cheltenham, UK; Northhampton, USA: Edward Elgar.

Dutrénit, G. (2007). The transition from building-up innovative technological capabilities to leadership by latecomer firms. Journal of Technology Innovation, Asian, 15(2), 125-149.

Ettlie, J. E. (1988). Taking charge of manufacturing how companiesare combining technological and organizational innovations to compete successfully. London: Jossey-Bass.

Revista de Administração e Inovação, São Paulo, v. 10, n.2, p.45-80, abr./jun. 2013. 
Figueiredo, P. N. (2001). Technological learning and competitive performance. Cheltenham, UK; Northampton, USA: Edward Elgar.

Figueiredo, P. N. (2003). Aprendizagem tecnológica e performance competitiva. Programa de pesquisa e aprendizagem tecnológica e inovação industrial. Revista de Administração Pública, 3(2), 323-361.

Figueiredo, P. N. (2004). Aprendizagem tecnológica e inovação industrial em economias emergentes: uma breve contribuição para o desenho e implantação para os estudos empíricos e estratégias no Brasil. Tradução de Luiz Alberto Monjardim. Rio de Janeiro: Editora Fundação Getulio Vargas.

Figueiredo, P. N. (2005). Acumulação tecnológica e inovação industrial: conceitos, mensuração e evidência no Brasil. São Paulo em Perspectiva, 19(1), 54-69.

Figueiredo, P. N. (2008). Industrial policy changes and firm-level technological capability development: evidence from Northern Brazil. World Development, 36(1), 55-88.

Hobday, M. (1995). Innovation in south-east Asia: lessons for Europe. Management Decision, 34(9), $37-48$.

Katz, J. (1976). Importación de tecnología, aprendizaje y industrialización dependiente. México: Fondo de Cultura Económica.

Katz, J. (1987). Technology generation in Latin America manufacturing industries. New York: St. Martin's Press.

Kim, L. (1997). Imitation to Innovation: the dynamics of Korea's technological learning. Boston, MA: Harvard Business School Press.

Kim, L. (1998). Technology policies and strategies for developing countries: lessons from the Korean experience. Technology Analysis \& Strategic Management, 10(3), 311-324.

Lall, S. (1992). Technological capabilities and industrialization. World Development, 20(2), 165-186.

Lundvall, B. (1992). National systems of innovation: towards a theory of innovation and interactive learning. London: Pinter.

Organisation de Coopération et de Développment Économiques (OECD) (1997). Technology, productivity and job creation: best policy practices highlights. Paris: OECD.

Organisation de Coopération et de Développment Économiques (OECD) (2005). Proposed guidelines for collecting and interpreting technological innovation data-Oslo Manual (3rd ed.). Paris: OECD.

Pavitt, K. (1991). Key characteristics of the large innovating firm. British Journal of Management, 2 , 41-50.

Penrose, E. (1959). The theory of the growth of the firm. London: Brasil Blackwell.

Pisano, G. (1997). The development factory: unlocking the potential of process innovation. Boston, MA: Harvard Business School Press. 
Schumpeter, J. A. (1934/1955). The theory of economic development: an inquiry into profits, capital, credit, interest and the business cycle. Cambridge, MA: Harvard University Press.

Tacla, C. L., \& Figueiredo, P. N. (2003). The dynamics of technological learning inside the latecomer firm: evidence from capital goods industry in Brazil. Int. J. Technology Management, 36(1/2/3), 6290.

Teece, D. J. (1980). The diffusion of an administrative innovation. Management Sciense, 26, 464-470.

Teece, D. J., \& Pisano, G. (1994). The dynamics capabilities of firms: an introduction. Industrial and Corporate Change, 3(3), 537-56.

Teece, D. J., Pisano, G., \& Shuen, A. (1997). Dynamic capabilities and strategic management. Strategic Management Journal, 18(7), 509-533.

Tidd, J., Bessant, J., \& Pavitt, K. (1997). Managing innovation: integrating technological, market and organizational change. Hoboken, NJ: John Wiley \& Sons.

Tiralap, A. (1990). The economics of the process of technical change of the firm: the case of the electronics industry in Thailand. Thesis of Doctorate, Philosophy in Science and Technology Policy Research, University of Sussex, Brighton.

Tremblay, P. J. (1998). Technological capability and productivity growth: an industrialised/industrializing country comparison. Montréal: CIRANO.

Tsekouras, G. (1998). Integration, organisation and management: investigating capability building. Thesis of Doctorate, SPRU, University of Sussex, Brighton.

Winter, S. G. (2006). Toward a neo-Schumpeterian theory of the firm. Industrial and Corporate Change, 15, 125-141. (Originally written in 1968. Several other authors comment in this (February) and the following (April) issue).

Yin, R. K. (2005). Estudo de caso: planejamento e métodos (3a ed.). Porto Alegre: Bookman. 


\title{
DEVELOPMENT OF NON-TECHNOLOGICAL CAPABILITIES AND THE ROLE OF THE UNDERLYING LEARNING PROCESSES: THE EXPERIENCE OF PETROBRAS
}

\begin{abstract}
This article examines the development of non-technological capabilities and their underlying learning processes. This relationship is examined in Petrobras (1957-2007) based on experiential long-term first-hand evidence gathered through extensive fieldwork. This study discloses that the accumulation of non-technological capabilities played an important role in the innovative performance of Petrobras. On the one hand, this study contributes to advancing our understanding of the nature of the non-technological capabilities. On the other hand, it draws the attention of managers to the significance of such capabilities which, although not purely technical, should not be neglected in the management efforts to improve the innovational performance on a corporate basis.
\end{abstract}

Key-words: Non-technological capabilities; Learning processes; Innovation performance; Petrobras.

Data do recebimento do artigo: 28/10/2012

Data do aceite de publicação: 14/02/2013

Revista de Administração e Inovação, São Paulo, v. 10, n.2, p.45-80, abr./jun. 2013. 